\title{
Safety, tolerability, and risks associated with first- and second-generation antipsychotics: a state-of-the-art clinical review
}

REVIEW

This article was published in the following Dove Press journal:

Therapeutics and Clinical Risk Management

29 June 2017

Number of times this article has been viewed

\begin{abstract}
Marco Solmi, ${ }^{1,2}$ Andrea Murru, ${ }^{3}$ Isabella Pacchiarotti, ${ }^{3}$ Juan Undurraga, ${ }^{4,5}$ Nicola Veronese, ${ }^{2,6}$ Michele Fornaro, ${ }^{7,8}$ Brendon Stubbs, ${ }^{2,9-11}$ Francesco Monaco, ${ }^{2}$ Eduard Vieta, ${ }^{3}$ Mary V Seeman, ${ }^{12}$ Christoph U Correll, ${ }^{13,14}$ André F Carvalho 2,15
\end{abstract}

'Neuroscience Department, University of Padua, ${ }^{2}$ Institute for Clinical Research and Education in Medicine, Padua, Italy; ${ }^{3}$ Bipolar Disorders Unit, Institute of Neuroscience, Hospital Clínic, University of Barcelona, IDIBAPS, CIBERSAM, Barcelona, Catalonia, Spain; ${ }^{4}$ Department of Psychiatry, Faculty of Medicine, Clínica Alemana Universidad del Desarrollo, ${ }^{5}$ Early Intervention Program, J. Horwitz Psychiatric Institute, Santiago, Chile; ${ }^{6}$ National Research Council, Ageing Section, Padua, ${ }^{7}$ Laboratory of Molecular and Translational Psychiatry, Department of Neuroscience, School of Medicine, University “Federico II", Naples, Italy;

${ }^{8}$ New York State Psychiatric Institute, Columbia University, New York, NY, USA; ' Health Service and Population Research Department, Institute of Psychiatry, Psychology and Neuroscience, King's College London, ${ }^{10}$ Physiotherapy Department, South London and Maudsley NHS Foundation Trust, London, "Faculty of Health, Social Care and Education, Anglia Ruskin University, Chelmsford, UK; ${ }^{12}$ Institute of Medical Science, Toronto, ON, Canada; ${ }^{13}$ Department of Psychiatry Research, Zucker Hillside Hospital, Northwell Health, Glen Oaks, ${ }^{14}$ Department of Psychiatry and Molecular Medicine Hempstead, Hofstra Northwell

School of Medicine, Hempstead, NY, USA; ${ }^{15}$ Translational Psychiatry Research Group and Department of Clinical Medicine,

Faculty of Medicine, Federal University of Ceará, Fortaleza, Ceará, Brazil

Correspondence: André F Carvalho Translational Psychiatry Research Group and Department of Clinical Medicine, Faculty of Medicine, Federal University of Ceará, Rua Professor Costa Mendes, $1608-4^{\circ}$ andar, 60430-140 Fortaleza, Ceará, Brazil

Fax +55 8533668054

Email andrefc7@hotmail.com
Abstract: Since the discovery of chlorpromazine (CPZ) in 1952, first-generation antipsychotics (FGAs) have revolutionized psychiatric care in terms of facilitating discharge from hospital and enabling large numbers of patients with severe mental illness (SMI) to be treated in the community. Second-generation antipsychotics (SGAs) ushered in a progressive shift from the paternalistic management of SMI symptoms to a patient-centered approach, which emphasized targets important to patients - psychosocial functioning, quality of life, and recovery. These drugs are no longer limited to specific Diagnostic and Statistical Manual of Mental Disorders $(D S M)$ categories. Evidence indicates that SGAs show an improved safety and tolerability profile compared with FGAs. The incidence of treatment-emergent extrapyramidal side effects is lower, and there is less impairment of cognitive function and treatment-related negative symptoms. However, treatment with SGAs has been associated with a wide range of untoward effects, among which treatment-emergent weight gain and metabolic abnormalities are of notable concern. The present clinical review aims to summarize the safety and tolerability profile of selected FGAs and SGAs and to link treatment-related adverse effects to the pharmacodynamic profile of each drug. Evidence, predominantly derived from systematic reviews, meta-analyses, and clinical trials of the drugs amisulpride, aripiprazole, asenapine, brexpiprazole, cariprazine, clozapine, iloperidone, lurasidone, olanzapine, paliperidone, quetiapine, risperidone, sertindole, ziprasidone, CPZ, haloperidol, loxapine, and perphenazine, is summarized. In addition, the safety and tolerability profiles of antipsychotics are discussed in the context of the "behavioral toxicity" conceptual framework, which considers the longitudinal course and the clinical and therapeutic consequences of treatment-emergent side effects. In SMI, SGAs with safer metabolic profiles should ideally be prescribed first. However, alongside with safety, efficacy should also be considered on a patient-tailored basis.

Keywords: antipsychotics, side effects, tolerability, safety, psychosis, psychiatry

\section{Introduction}

Severe mental illness (SMI), including major depressive disorder (MDD), bipolar disorder (BD), and schizophrenia spectrum disorders, represents a major public health issue, accounting for significant health and social and economic burden worldwide. ${ }^{1-5}$ The chronic nature of SMI is characterized by recurring episodes, ${ }^{6,7}$ residual symptom burden, and a variable degree of cognitive dysfunction and functional impairment, which may persist even during periods of remission. ${ }^{8-13}$ In addition, growing evidence indicates that acute, and especially chronic, manifestations are only partially addressed with first-line, approved treatments. ${ }^{14}$ More recently, the use of atypical or second-generation antipsychotics (SGAs) has been extended to cover a wide 
range of psychiatric conditions besides schizophrenia and schizoaffective disorders. They have become especially popular as add-on treatment for patients with MDD who fail to adequately respond to antidepressants, ${ }^{15}$ for $\mathrm{BD},{ }^{16-18}$ and for behavioral symptoms associated with dementia. ${ }^{19,20}$ In addition, systematic evidence and meta-analysis indicate that SGAs are frequently used for several off-label indications; ${ }^{21,22}$ they have been advocated as "multidimensional" agents. ${ }^{23}$

Since the serendipitous discovery of chlorpromazine (CPZ) for psychosis in 1952, first-generation antipsychotics (FGAs) have revolutionized psychiatric care, leading to across-the-board discharges from long-stay institutions and marked reductions in hospitalization rates. ${ }^{24}$ Until the 1950s, patients suffering from SMI often required prolonged hospitalization, sometimes lifetime institutionalization, and were offered remedies with little or no evidence of benefit. The situation improved upon the development of FGAs, which allowed for safe and effective treatment in the community. ${ }^{25}$ The introduction of FGAs led to good control of behavioral and symptomatic domains in SMI (especially true for "positive" symptoms such as delusions and hallucination), due to a heterogenous combination of strong D2 blockade and anticholinergic and antihistaminergic actions. ${ }^{26,27}$ Yet, this success turned out to be only partial because FGAs did not help and often had a deleterious impact on negative, cognitive, affective, and/or motor domains. ${ }^{28}$ With the rediscovery of clozapine (CLO), ${ }^{29,30}$ SGAs, which combined potent (5HT2A) serotonergic blockade with potent but "fast-off" dopamine D2 blockade, were developed. The range of therapeutic indications was broadened, and there was a progressive shift from a paternalistic behavioral control of SMI symptoms to a more patient-centered approach, which valued improved psychosocial functioning and quality of life. ${ }^{31-33}$ Since the early 2000 s, the development of antipsychotics with partial agonism at dopamine D2 receptors has led several authors to speak of a class of "third-generation" antipsychotics. ${ }^{34}$ However, the lack of a third neuroreceptor system related to efficacy has for the most part prevented the widespread adoption of this terminology. Compared to the pharmacodynamic profile of FGAs, that of SGAs has a less specific antagonistic action at the $\mathrm{D} 2$ receptor and often a relatively stronger serotonin 5HT2A receptor action, as well as variable alpha adrenergic, antihistaminergic, and anticholinergic activities, plus exhibits a varying affinity at other (sub-) receptor types. ${ }^{35}$ Over the past 20 years, the main tolerability concerns have shifted from the sometimes disabling and always stigmatizing extrapyramidal adverse effects of FGAs to cardiometabolic issues that affect health and life span and are associated - to varying degrees with SGAs. ${ }^{35-39}$

Despite the widespread use of SGAs, many concerns have been raised regarding their safety and tolerability. Safety issues vary according to patient populations and across various compounds. For example, the appropriateness of SGA use has been debated in patients with dementia due to an increased incidence of cerebrovascular events and death compared to placebo. ${ }^{21,40}$ Furthermore, different SGAs differentially induce treatment-emergent weight gain and metabolic disturbances, ${ }^{41}$ among other side effects, thus affecting drug tolerability and safety ${ }^{36,42}$ to different degrees. Given that these drugs usually need to be taken indefinitely, tolerability ${ }^{43}$ and treatment adherence, ${ }^{44,45}$ and their relationship to outcomes in SMI, ${ }^{46}$ must always be considered alongside with efficacy.

Hence, the main objective of this review is to critically review the literature in order to provide clinically oriented state-of-the-art coverage of the safety and tolerability profile of selected FGAs and SGAs in SMI. The secondary objective is to provide a succinct overview of possible pharmacological mechanisms underpinning differences in tolerability and safety among SGAs and to interpret tolerability data according to the "behavioral toxicity" framework. ${ }^{47-49}$ This refers to treatment-induced alterations in mood, perception, cognition, and psychomotor function, all of which can potentially worsen illness course.$^{50}$ Importantly, some of these untoward effects may persist long after drug discontinuation. ${ }^{50,51}$ Such phenomena are captured by the term iatrogenic comorbidity, ${ }^{50,51}$ a negative outcome of the treatment of psychosis whose unfortunate pervasiveness is this review hopes to reduce.

\section{Methods}

This is a narrative review of selected side effects (Table 1) based on a PubMed/MEDLINE database search on December 20, 2016, using the following search terms: "second-generation antipsychotic" OR "SGA*" OR "atypical antipsychotic" cross-referenced with "drug-related side effects and adverse reactions" [Mesh] OR "specific side effects" (Table 1), without publication date or language limit. We synthesized the evidence in a best evidence synthesis and considered largescale observational studies, randomized controlled trials (RCTs), previous meta-analyses, or systematic reviews (SRs), and single-drug package insert data as well. When none of the former options were available, we also considered case reports for preliminary emerging evidence not otherwise covered in the literature. 
Table I Main treatment-emergent adverse events related to the use of antipsychotics

Adverse effects and behavioral toxicity of antipsychotics at therapeutic doses

Sedation

Cognitive impairment

Weight gain and obesity

Metabolic syndrome and its components (waist circumference,

dyslipidemia, high fasting blood sugar, diabetes mellitus, and

hypertension)

Neuromotor adverse effects (EPS, bradykinesia, dystonia, akathisia,

and TD)

Seizures

QTc prolongation, HRV, and SCD

Hypotension

Myocarditis and cardiomyopathy

Coronary heart disease and stroke

Pneumonia and acute respiratory failure

Pulmonary embolism and venous thromboembolism

Gastrointestinal adverse effects (eg, nausea, vomiting, diarrhea, and constipation)

Dry mouth, sialorrhea, and dental caries

Liver toxicity

Urinary and kidney dysfunction

Leucocytopenia, agranulocytosis, and thrombocytopenia

Osteopenia, osteoporosis, and fractures

Falls

Binge eating, impulse discontrol, and gambling

Tobacco use and smoking

Sexual and reproductive system dysfunction

Endocrine adverse effects (diabetes ketoacidosis, hypothyroidism, and hyponatremia)

Hyperprolactinemia and prolactinoma

Breast and cervical cancers

Malignant neuroleptic syndrome

Use in pregnancy and breastfeeding

Withdrawal syndromes

Rebound syndromes

Abbreviations: EPS, extrapyramidal symptoms; TD, tardive dyskinesia; HRV, hear rate variability; SCD, sudden cardiac death.

\section{Adverse effects and behavioral toxicity related to antipsychotic use}

Table 2 summarizes the selected pharmacodynamic receptor profile of several FGAs and all marketed SGAs in Europe and the US. A detailed overview of drug specific tolerability and safety profiles is reported in Table 3 . We considered selected FGAs (CPZ, haloperidol (HAL), loxapine [LOX], molindone $[\mathrm{MOL}]$, and perphenazine [PER]) and the SGAs amisulpride (AMI), aripiprazole (ARI), asenapine (ASE), brexpiprazole (BRE), cariprazine (CAR), CLO, iloperidone (ILO), lurasidone (LUR), olanzapine (OLA), paliperidone (PALI), risperidone (RIS), quetiapine (QUE), sertindole (SER), and ziprasidone (ZIP).

\section{Sedation}

Sedation can be a therapeutic target in the acute treatment of SMI patients presenting with agitation or severe behavioral symptoms but is also a safety concern and should be avoided in the long-term treatment due to its relationship with adverse effects on cognitive performance, physical activity/ sedentary behavior/body weight, and patients' satisfaction with therapy, among others, as shown in an influential metaanalysis and randomized clinical trials..$^{28,52}$ Sedation is linked with the blockade of histaminergic receptors and is highest for CLO, zotepine, and CPZ, gradually decreasing from QUE, OLA, ZIP, ASE, HAL, and RIS to LUR, ARI, ILO, SER, PALI, and AMI, as shown in a comparative meta-analysis of trials of acute antipsychotic use in schizophrenia. ${ }^{28}$ Rather than being sedative, CAR shows an activating profile according to its high number in a number needed to harm trial. ${ }^{53}$ In $\mathrm{BD}$, a recent meta-analysis showed surprisingly comparable sedation between ARI and other SGAs,${ }^{54}$ which may be an artifact due to frequent benzodiazepine coadministration in the beginning of trials in acute BD mania or may be associated with ARI itself, particularly at doses $>20 \mathrm{mg} /$ day.

\section{Cognitive impairment}

FGAs and SGAs can both impair cognitive functions in the first-episode schizophrenia, with the former being linked to a worse profile, as shown in a meta-analysis. ${ }^{55}$ The cognitive effect of antipsychotics is a complex domain, which can be influenced by baseline cognitive ability, ${ }^{56}$ plus anxiety, mood, positive, negative, and residual symptoms in patients with schizophrenia. Considered as a unique domain, cognitive performance is negatively influenced by high doses of drugs with strong anticholinergic properties and with strong $\mathrm{D}_{2}$ blockade in patients with schizophrenia, as shown by several RCTs. ${ }^{57,58}$ Consequently, while RIS and HAL can impair cognitive function through a decrease in dopamine transmission, CLO, OLA, and QUE exert similar effects perhaps through more potent anticholinergic activity and also because they are potent $\mathrm{D} 2$ blockers in their own right (but for shorter periods of time). Moreover, it is not clear whether coadministration of anticholinergic drugs for extrapyramidal symptoms (EPS) and dampening of motivation may confound net effect of antipsychotics on cognition. Since cognitive function benefits indirectly from an improvement in hallucinations and thought disorganization ${ }^{59}$ due to antipsychotic administration, the net effect on cognition is often null, as reported in RCTs and SRs. ${ }^{60,61}$ However, cognition is frequently reported only as a secondary outcome, or not reported at all, as shown in SRs of RCTs of SGAs in schizophrenia. ${ }^{62,63}$ It has been hoped 
Table 2 Neuroreceptor binding profiles of antipsychotics

\begin{tabular}{|c|c|c|c|c|c|c|c|c|}
\hline Drug & $K_{i} \mathrm{D} 2$ & $K_{i}$ 5HTIA & $K_{i} 5 \mathrm{HT} 2 \mathrm{~A}$ & $K_{i} 5 \mathrm{HT} 2 \mathrm{C}$ & $K_{i} \alpha I$ & $K_{i} \propto 2$ & $K_{i} \mathrm{HI}$ & $K_{i} \mathrm{M} 2$ \\
\hline$C P Z$ & 3 & 2,115 & 4.06 & 32.5 & 2.6 & 750 & 3 & 244 \\
\hline$H A L$ & 2.6 & 1,800 & 61 & 4,700 & 17 & 600 & 260 & $>10,000$ \\
\hline LOX & 9.8 & $N A$ & 2 & $N A$ & 250 & NA & 14.9 & $N A$ \\
\hline$M O L$ & 120 & 3,797 & 5,000 & $>10,000$ & 2,500 & 625 & $>10,000$ & $N A$ \\
\hline PER & 1.4 & 421 & 5 & 132 & 10 & 500 & 8 & $N A$ \\
\hline AMI & 1.3 & $>10,000$ & 2,000 & $>10,000$ & 7,100 & $\mathrm{I}, 600$ & $>10,000$ & NA \\
\hline ARI & \pm 0.7 & \pm 5.5 & 8.7 & 22 & 26 & 74 & 30 & 3,510 \\
\hline ASE & 1.3 & 2.5 & 0.06 & 0.03 & 1.2 & 1.2 & I & $>10,000$ \\
\hline BRE & \pm 0.3 & \pm 0.12 & 0.47 & NA & 3.8 & 0.59 & 19 & NA \\
\hline CAR & \pm 0.5 & \pm 2.6 & 18.8 & 134 & 155 & NA & 23.2 & $>10,000$ \\
\hline CLO & 210 & 160 & 2.59 & 4.8 & 6.8 & 158 & 3.1 & 204 \\
\hline ILO & 6.3 & 168 & 5.6 & 14 & 4.7 & 4.7 & 437 & 3,311 \\
\hline LUR & 1 & \pm 6.4 & 0.5 & NA & NA & 11 & $>10,000$ & $>10,000$ \\
\hline OLA & 20 & 610 & 1.5 & 4.1 & 44 & 280 & 0.1 & 622 \\
\hline PALI & 2.8 & 480 & 1.2 & 48 & 10 & 80 & 3.4 & $>10,000$ \\
\hline RIS & 3.8 & 190 & 0.1 & 32 & 2.7 & 8 & 5.2 & $>10,000$ \\
\hline QUE & 770 & 300 & 31 & 3,500 & 8.1 & 80 & 19 & 630 \\
\hline SER & 2.7 & 2,200 & 0.14 & 6 & 3.9 & 190 & 440 & NA \\
\hline ZIP & 4.8 & \pm 3.4 & 0.4 & 1.3 & 10 & 154 & 4.6 & $>3,000$ \\
\hline \multicolumn{9}{|c|}{ Effects related to receptor blockade } \\
\hline & $\begin{array}{l}\text { EPS, } \\
\text { hyperprolactinemia, } \\
\text { sexual dysfunction, } \\
\text { and cognitive } \\
\text { dysfunction }\end{array}$ & $\begin{array}{l}\text { Anxiolytic and } \\
\text { antidepressant } \\
\text { effects }\end{array}$ & $\begin{array}{l}\text { Lower } \\
\text { incidence of } \\
\text { akathisia and } \\
\text { parkinsonism }\end{array}$ & $\begin{array}{l}\text { Weight } \\
\text { gain and } \\
\text { metabolic } \\
\text { effects }\end{array}$ & $\begin{array}{l}\text { Hypotension, } \\
\text { priapism, } \\
\text { retrograde } \\
\text { ejaculation, } \\
\text { and low libido }\end{array}$ & Antidepressant & $\begin{array}{l}\text { Appetite, } \\
\text { sedation, cognitive } \\
\text { dysfunction, and } \\
\text { weight gain }\end{array}$ & $\begin{array}{l}\text { Cognitive } \\
\text { dysfunction, urinary } \\
\text { retention, glaucoma, } \\
\text { constipation, and } \\
\text { dry mouth }\end{array}$ \\
\hline
\end{tabular}

Notes: Lower $K_{i}$ (ie, nanomolar concentration at which $50 \%$ of the respective receptor type is occupied) means higher affinity. Light gray, FGAs; \pm , partial agonism for the specific receptor. Italics represent FGAs. Data from Correll. ${ }^{35}$

Abbreviations: CPZ, chlorpromazine; HAL, haloperidol; LOX, loxapine; NA, not applicable; MOL, molindone; PER, perphenazine; AMI, amisulpride; ARI, aripiprazole; ASE, asenapine; BRE, brexpiprazole; CAR, cariprazine; CLO, clozapine; ILO, iloperidone; LUR, lurasidone; OLA, olanzapine; PALI, paliperidone; RIS, risperidone; QUE, quetiapine; SER, sertindole; ZIP, ziprasidone; EPS, extrapyramidal symptoms; FGAs, first-generation antipsychotics; FGA, first-generation antipsychotics.

that ARI would, unlike other antipsychotic drugs, improve cognition. The drug may ameliorate pre-attentive functions, ${ }^{64}$ possibly due to both its partial D2 agonism and its almost absent affinity to cholinergic receptors. However, clinical data from RCTs do not seem to confirm such a priori expectations, as they show no change in cognitive function when ARI or BRE are administered to patients with schizophrenia. ${ }^{65}$ Furthermore, no difference in effects on cognitive function emerged when ARI was meta-analytically compared with other antipsychotics in schizophrenia. ${ }^{66}$

\section{Weight gain and obesity}

Although most high-potency FGAs have relatively little weight gain potential, low-potency FGAs and most SGAs can substantially increase the risk of weight gain and ultimately of obesity in schizophrenia. ${ }^{36,42,67}$ However, the weight gain potential differs substantially among SGAs, and certain FGAs can even induce more weight gain than specific SGAs. In particular, while HAL, ZIP, LUR, ARI, BRE, CAR and AMI are associated with little weight gain, at least in chronic patients who are often already overweight, PALI, RIS, and
QUE induce moderate weight gain, SER, CPZ, ILO, strongly increase body weight, with extreme body mass index (BMI) increases with treatment by CLO, zotepine, and OLA. ${ }^{28,68}$ There seems to be less consensus regarding ASE, which has been described by different SRs as either one of the SGAs with least weight gain ${ }^{28}$ or as a weight neutral $\operatorname{drug}^{68}$ in schizophrenia. In any case, all antipsychotics are associated with often substantial weight gain, especially evident when treating antipsychotic-naïve patients. ${ }^{69,70}$

\section{Metabolic syndrome and its components (waist circumference, dyslipidemia, diabetes mellitus, and hypertension)}

Metabolic syndrome is defined by the presence of three or more of five criteria, including increased waist circumference (central obesity), elevated blood pressure, low highdensity lipoprotein cholesterol, hypertriglyceridemia, and hyperglycemia. ${ }^{71}$ Since patients with metabolic syndrome are at an increased risk of cardiovascular disease (CVD) ${ }^{71}$ drugs with a more favorable metabolic profile are preferred in BD and schizophrenia. ${ }^{36}$ Antipsychotics can directly or 


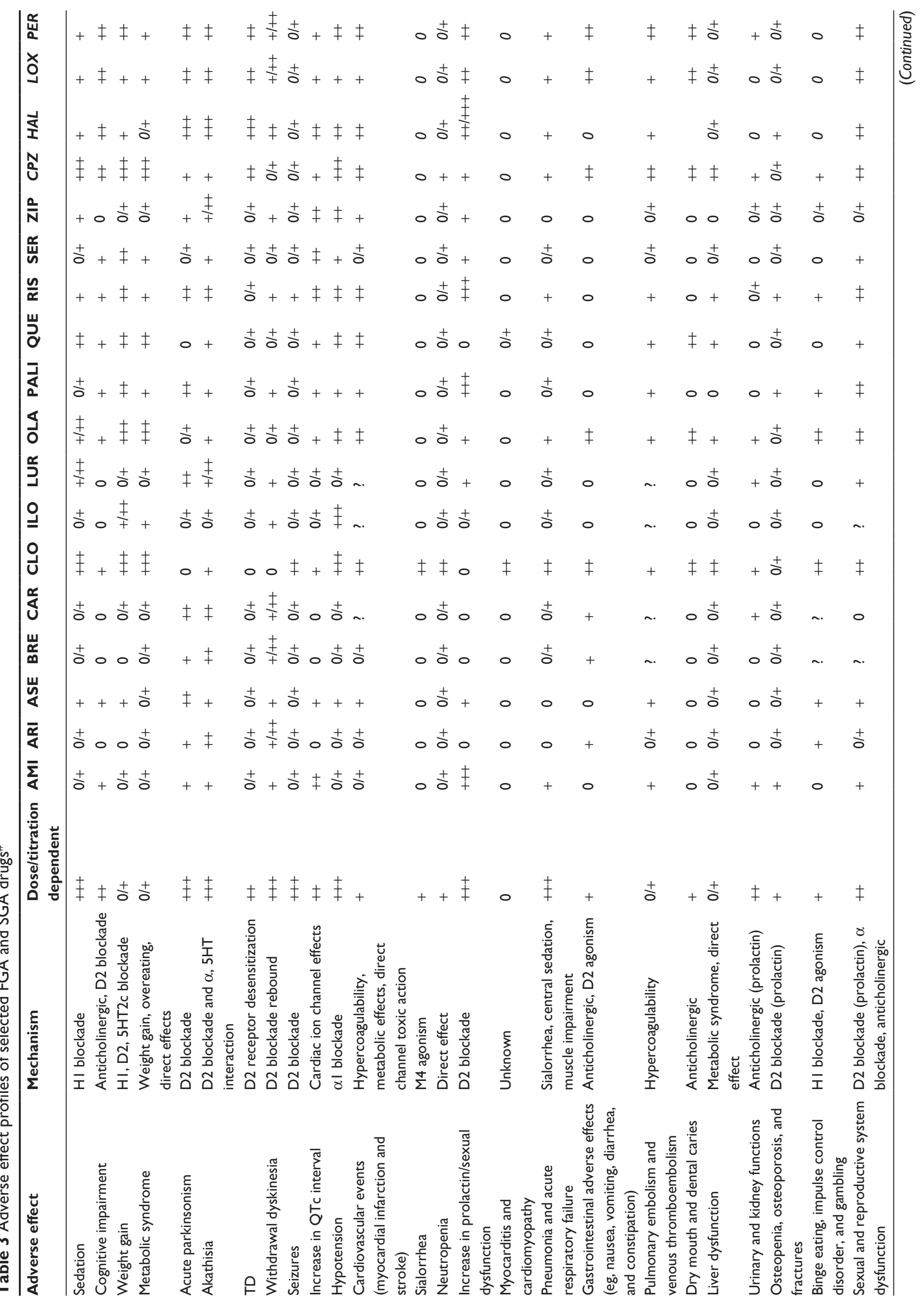


indirectly adversely affect cardiometabolic health in various ways, ranging from increasing appetite and food intake ${ }^{72}$ to a more sedentary lifestyle linked to sedation or EPS $;{ }^{73}$ however, it has been shown that cardiometabolic adverse effects of antipsychotics are to some degree independent of lifestyle parameters. ${ }^{74}$ Polypharmacotherapy increases the risk of metabolic syndrome. ${ }^{38}$ A meta-analysis showed that both FGAs and SGAs increase the risk of metabolic syndrome compared to a no drug condition in SMI. ${ }^{36}$ According to the same meta-analysis and individual studies, the metabolic liability of antipsychotics ranges broadly, the lowest risk associated with ARI, BRE, CAR, LUR, ZIP, and highpotency FGAs (HAL) and the highest risk associated with CPZ, CLO, OLA, and QUE. All other antipsychotics are considered as having a medium/intermediary risk. ${ }^{36}$ Longer term data are still lacking with the newest SGAs, BRE, and CAR.

\section{Neuromotor side effects (EPS, bradykinesia, dystonia, akathisia, and tardive dyskinesia)}

EPS, including bradykinesia, muscle rigidity, tremor, dystonia, akathisia, and tardive dyskinesia (TD), are linked to the ratio of $\mathrm{D}_{2}$ receptor to $5 \mathrm{HT} 2 \mathrm{~A}$ receptor binding. According to several meta-analyses, ${ }^{28,75}$ the highest incidence of EPS in patients with schizophrenia occurs with HAL, with moderate EPS being observed with RIS, PALI, and LUR, down to CPZ; milder EPS being observed with ASE, ZIP, AMI, ILO, and ARI; and still milder EPS being observed with QUE, OLA, SER, and CLO. Although CAR is a partial D2 agonist, it seems to increase the risk of EPS according to a recent meta-analysis across SMI, ${ }^{76}$ perhaps due to relatively weak 5HT2A antagonism (or more antagonism than agonism). Perhaps because of illness-induced serotonin disturbance, BD patients, especially in depression, have been found in one meta-analysis to be more vulnerable to acute movement disorders secondary to antipsychotics than patients with schizophrenia. ${ }^{77}$

Akathisia, defined as a compelling need for constant motion, associated with marching up and down, crossing and uncrossing the legs when sitting, and improving after drug dose reduction or coadministration of benzodiazepines, should be differentiated from pseudoakathisia. ${ }^{78,79}$ The latter is characterized by inner restlessness as a sign of pharmacodynamic or pharmacokinetic rebound-induced restlessness and improves when the dose of an antipsychotic is increased. Akathisia can occur with both FGAs and SGAs, but FGAs are more likely to produce clinically relevant akathisia as per one meta-analysis. ${ }^{55}$ Comparative meta-analyses show 
that ARI induces more akathisia than OLA in schizophrenia and BD, CLO and RIS more than ZIP, and RIS more than SER. ${ }^{54,75}$ It should be noted that some overlap between akathisia and pseudo-akathisia labeling may have influenced these results.

Compared to FGAs, an up to sixfold lower incidence of TD, tardive dystonia, and tardive akathisia occurs with SGAs in schizophrenia. ${ }^{80,81}$ Some evidence pointed to a possible increased risk for TD in populations with BD.$^{82}$ Nonetheless, data on the incidence of TD in BD are substantially lacking or else are totally missing as in the case of long-acting depot RIS. ${ }^{83}$ ARI has been associated with TD, in particular when high doses are prescribed, in female elderly patients in particular. ${ }^{84}$

While an association between some genetic polymorphisms ${ }^{85,86}$ and TD has been described in patients with schizophrenia, there is no consensus about a genetic predisposition to $\mathrm{TD} .{ }^{87}$ On the other hand, several clinical variables have consistently predicted TD occurrence in schizophrenia in observational studies, RCTs, and reviews; these include anticholinergic medication; older age; intermittent antipsychotic treatment; high cumulative dose; higher negative, cognitive, and affective symptoms; and early movement side effects. ${ }^{88-91}$ At present, no specific SGA can be considered as conferring a higher TD risk than others in schizophrenia. ${ }^{92}$

\section{Seizures}

A World Health Organization (WHO) adverse drugs reaction database study hypothesized a higher risk for seizures not only with SGAs than FGAs, especially with CLO, but also with OLA and QUE. ${ }^{93}$ Yet, this contrasts with the results of a recent meta-analysis finding a slightly increased risk for seizures with FGAs compared to SGAs. Still, CLO seems associated with a higher seizure risk in patients with either BD or schizophrenia compared to other SGAs. ${ }^{94,95}$ One population-based study reported an increased risk of antipsychotic-related seizures with CLO and HAL, finding a lower risk with ARI compared with RIS. Clinical variables, such as younger age, a diagnosis of schizophrenia versus BD, and higher antipsychotic doses may help to identify subpopulations at higher risk for treatment-emergent seizures, but no causal inference can be made based on cross-sectional data. ${ }^{95}$ While a precise mechanism is unknown, a role of D2 and D3 receptors has been suggested. ${ }^{96}$

\section{QTc prolongation, heart rate variability, and sudden cardiac death}

Patients with schizophrenia have shown a proneness to rhythm alterations, such as Brugada syndrome. ${ }^{97}$ In addition to such a predisposition, cardiac electrical activity can be altered by antipsychotic use, resulting in QTc prolongation, even in younger patients, in particular in women. ${ }^{98,99}$ In adults, QTc prolongation is generally clinically relevant when QTc is >500 milliseconds or when QTc increases by $\geq 60$ milliseconds from drug-free baseline, ${ }^{39}$ resulting in an increased risk of torsades de pointes and sudden cardiac death (SCD). QTc alterations may start as early as 2 weeks after the beginning of antipsychotic treatment in the first-episode schizophrenic patients. ${ }^{100}$ In a recent, nationwide study, use of any antipsychotics was associated with a 1.5-fold increased risk of ventricular arrhythmia and/or SCD, being somewhat higher with FGAs (odds ratio [OR] $=1.66,95 \%$ CI 1.43-1.91) than with SGAs (OR $=1.36,95 \%$ CI 1.20-1.54), ${ }^{101}$ with an increased risk of up to 5.8-fold, depending on the definition of SCD. ${ }^{39}$

In an observational study of patients with BD, SGAs were shown to decrease heart rate variability (HRV), in particular those drugs with high affinity for the D2 receptor. ${ }^{102}$ Since HRV is a recognized predictor of SCD, routine monitoring of HRV may help in identifying at-risk subjects and possibly prevent SCD. ${ }^{103}$ According to several meta-analyses and individual studies on schizophrenia, ARI, BRE, CAR, and ILO do not seem to have a clinically relevant effect on QT in schizophrenia, whereas ASE, CLO, OLA, and QUE may have a moderate effect, and finally, AMI, PALI, RIS, ZIP, and SER as well as thioridazine have been associated with the highest QT prolongation. ${ }^{28,104-106}$

\section{Hypotension}

Hypotension is a relevant side effect, which can be complicated with syncope. Falls sometimes lead to hip fracture, transient ischemic attacks, myocardial infarction in rare occasions, and, ultimately, to death in the most severe cases. ${ }^{107}$ Orthostatic (or postural) hypotension is thought to be mediated by $\alpha-1$ receptor blockade and should be expected from antipsychotics with a high affinity to this receptor, such as ILO, ZIP, RIS, QUE, ASE, HAL, CPZ, and PER, ${ }^{108}$ according to animal models. In human beings, CLO, among SGAs, most increases the risk of hypotension, especially at the beginning of treatment, which is the reason behind low initial doses. ${ }^{94}$

\section{Myocarditis and cardiomyopathy}

Although not a frequent event, myocarditis risk is highest with CLO, being associated with troponin and C-reactive protein elevation, and eosinophilia. ${ }^{109}$ Emerging but sparse case reports also describe cases of myocarditis with QUE. ${ }^{110,111}$ In general, regular medical examination as well as blood examination and routine electrocardiography when symptoms arise 
(fatigue, palpitations, arrhythmias, shortness of breath upon exertion or at rest, dizziness) can help detect myocarditis and cardiomyopathy early. ${ }^{112}$ Early data suggested that successful rechallenge with CLO after myocarditis may be possible in some cases. ${ }^{113}$

According to a large observational study, cardiomyopathy may occur as well with CLO, potentially leading to heart failure. ${ }^{114}$ Echocardiography is the gold standard procedure to detect and monitor cardiomyopathy.

\section{Coronary heart disease and stroke}

Subjects affected by SMI, including BD and schizophrenia, have consistently been shown to have an up to twofold increased risk of stroke and acute myocardial infarction (AMI), according to several meta-analyses. ${ }^{115-118}$ FGAs and SGAs appear to contribute to the increased risk of stroke $(\mathrm{OR}=1.58,95 \% \text { CI 1.01-2.49) })^{119}$ and AMI (OR $=1.88,95 \%$ CI 1.39-2.54). ${ }^{120}$ Comparative data providing information about different SGAs are sparse, and in particular, the cardiovascular safety of newer SGAs, such as ILO, LUR, $\mathrm{BRE}$, and CAR, is missing. In the elderly, higher mortality with FGAs than SGAs seems to be partially explained by a greater risk for stroke and AMI (in addition to ventricular arrhythmias and hip fracture). ${ }^{121}$ Broadly, in SMI, HAL, CPZ, OLA, RIS, and QUE have shown the strongest association with cardiovascular events. ${ }^{69,122-126}$ The main mechanism through which antipsychotic agents increase CVD rates is through their metabolic effects on weight and glucose and lipid metabolism; ${ }^{36,37,127}$ however, some direct toxic action has also been hypothesized based on animal models, in particular involving potassium and calcium channel currents. ${ }^{128-130}$

\section{Pneumonia, acute respiratory failure, and sleep apnea}

Two large observational studies suggest that, in patients with schizophrenia, CLO may result in an increased incidence of pneumonia, which persists after CLO is withdrawn and returns when it is reintroduced. This has been associated with sialorrhea. ${ }^{131-133}$ There is evidence suggesting that this risk is dose related, in particular with CLO, and is higher in the first weeks of therapy and in elderly patients. ${ }^{132,134}$ Polypharmacotherapy may further increase pneumonia risk. ${ }^{132}$ While ARI and ZIP do not seem to increase the risk of pneumonia, OLA and RIS increase pneumonia occurrence more than QUE in the elderly population, ${ }^{135}$ but no dose-dependent effect has been observed. ${ }^{132}$ A meta-analysis including a wider group of patients beyond schizophrenia and BD clearly showed that both FGAs and SGAs increase the risk of pneumonia. ${ }^{136}$ More meta-analytic evidence suggested that pneumonia accounts for the higher mortality of FGAs over SGAs. ${ }^{137}$ Most importantly, this difference between FGAs and SGAs was confirmed in both elderly and young adult populations. ${ }^{136}$ Finally, when prescribing antipsychotics to patients with chronic obstructive pulmonary disease, a frequent comorbidity in BD and schizophrenia, ${ }^{138,139}$ respiratory function should be strictly monitored since there is a $>1.5$ fold increased risk of acute respiratory failure. ${ }^{140}$ In case of overdose of AP, respiratory depression can occur as well, due to central sedation and peripheral respiratory muscle impairment. ${ }^{141}$

Sleep apnea moreover has been shown to be more frequent in patients taking SGAs compared with those not on SGAs ${ }^{138}$ even after analyses were adjusted for several relevant confounding factors in a large observational study. ${ }^{142}$ It could be argued that compounds that increase the risk of weight gain consequently increase the risk of sleep apnea; no specific SGA, however, has shown a worse profile than others.

\section{Pulmonary embolism and venous thromboembolism}

Patients with schizophrenia on antipsychotic treatment show a global hypercoagulability state. ${ }^{143}$ Pulmonary embolism is a severe adverse event that can occur with antipsychotics, with the concomitant prescription of both FGAs and SGAs increasing the risk from potential substantial harm to a fourfold increased risk, as clearly shown in large observational studies and a meta-analysis. ${ }^{144,145}$ Similarly, considering both pulmonary embolism and venous thromboembolism together, some evidence suggests that low-potency FGAs and SGAs have a worse safety profile than high-potency FGAs. ${ }^{145-147}$ However, only sparse data are available for individual drugs or specific diagnostic groups. ${ }^{145}$ Special attention should be paid in pregnancy and the immediate postpartum, two conditions at increased risk for thrombosis per se.

\section{Gastrointestinal adverse effects}

A cross-sectional study of patients with schizophrenia showed that among all antipsychotics, CLO seems to induce the most severe constipation, prolonging colon transit time by up to almost five times, irrespective of gender, age, ethnicity, or length of treatment, undermining treatment adherence. ${ }^{148}$ This is likely due to the anticholinergic action ${ }^{149}$ and is a dangerous side effect which patients should be monitored for, given the reduced pain sensitivity demonstrated in schizophrenia. ${ }^{150,151}$ OLA, CLO, and low-potency FGAs substantially impair colon transit, while drugs with low affinity to cholinergic 
receptors, such as BRE, CAR, LUR, and PALI, do not. ${ }^{152}$ Conversely, according to a recent meta-analysis on schizophrenia, ARI has been reported to reduce constipation when co-administered with other antipsychotics. ${ }^{153} \mathrm{D}_{2}$ antagonists have been reported to reduce nausea (the early FGAs were widely used for nausea of pregnancy), ${ }^{153}$ but the partial D2 agonists, such as CAR, BRE, and ARI, can induce nausea, typically within the first 4 weeks of treatment. ${ }^{154,155}$

\section{Dry mouth, drooling/hypersalivation, and dental caries}

Dry mouth is an anticholinergic side effect, most frequent with CLO, OLA, QUE, and low-potency FGAs, that increases the risk of dental caries according to a large population-based study. ${ }^{156}$ Sialorrhea is a frequent and paradoxical side effect of CLO ${ }^{157}$ Hypersalivation substantially impairs quality of life and may interfere with social functioning, but has, however, been reported to prevent dental caries. ${ }^{156}$ Yet, intense sialorrhea may bear important consequences, such as an increased risk for aspiration pneumonia. ${ }^{133}$ ARI has been reported to reduce drooling/hypersalivation, according to a meta-analysis, ${ }^{153}$ when antipsychotic polypharmacotherapy is used in schizophrenia.

\section{Hepatotoxicity}

The precise pathogenesis of liver damage with the use of antipsychotics is unknown. Several hypotheses have been proposed, but no unique mechanism has been detected since FGAs and SGAs comprise a group of molecules with largely different chemical structures, pharmacokinetics, and pharmacodynamics. ${ }^{158}$ Continuous use of antipsychotics is associated with abnormal liver function tests in up to $78 \%$ of patients, as shown by an SR. ${ }^{158}$ Generally, such alterations consist of elevated transaminases or cholestatic indices, which often occur within the first 6 weeks of treatment, remaining stable or resolving with continuous treatment. ${ }^{158}$ Although asymptomatic liver enzyme abnormalities may be common, significant liver enzyme elevations are rare, but can occur with OLA, QUE, and RIS. ${ }^{159} \mathrm{CPZ}$ has been most frequently associated with acute liver injury, even resulting in fatal hepatic failure, but such events are rare with other antipsychotics. ${ }^{158}$ Sparse comparative data are available, but CLO seems to confer a relatively high risk of liver damage, in particular compared with HAL. ${ }^{160}$ SGAs have been associated with chronic liver disease in patients with BD in a large observational study. ${ }^{161}$ During the first 3 years of antipsychotic treatment in patients with the first-episode schizophrenia, nonalcoholic fatty liver disease was associated with the presence of the major components of metabolic syndrome in an RCT. ${ }^{162}$ Liver function should be monitored in patients administered SGAs. ${ }^{163}$ Predisposing factors to liver damage include not only older age, high daily dosage/ serum concentrations, alcohol abuse, and a history of hepatic disease ${ }^{160}$ but also some of the evidence-based combination treatments for $\mathrm{BD}$, such as valproate. ${ }^{164}$ PALI, which does not undergo first-pass hepatic metabolism, and ZIP, which is only partially metabolized by cytochrome P450 enzymes, are safest for the liver.

\section{Urinary and kidney function}

PALI, CLO, ILO, OLA, QUE, and RIS are excreted in urine, while ARI and ZIP are excreted in feces so that these two drugs do not require dose adjustment in patients with renal impairment, at least regarding their oral formulations. ${ }^{39}$ Conversely, LUR requires dose adjustment when renal failure is present, and CAR and AMI, which are solely excreted by the kidneys, should be avoided in case of renal failure. ${ }^{165}$ Moreover, since electrolyte disturbances can occur when renal function is impaired, AMI and SER should be used with caution and with accompanying electrolyte monitoring due to potential cardiac toxicity. Drugs with strong anticholinergic properties, such as CLO, OLA, and low-potency FGAs, can induce acute urinary retention, but urinary acute retention can also occur with ZIP or RIS, via central dopaminergic and serotoninergic mechanisms as described in an SR. ${ }^{166}$ SGAs should be used with caution in particular in the elderly due to their role in increasing the risk for hospitalization for acute kidney injury ${ }^{167}$ and hypotension with risk of falls, as documented by a cohort study involving older adults. On the other hand, antipsychotics with strong sedative effects can cause urinary incontinence, as can be the case with CLO, especially when associated with antipsychotic polypharmacotherapy. ${ }^{168,169}$ Although evidence on the topic is substantially lacking, nevertheless, the known adverse effects on kidney function after very long-term lithium treatment give rise to the recommendation that special caution be paid in patients on lithium combined with PALI, CLO, ILO, OLA, QUE, and RIS, a common drug regimen in evidence-based guidelines for BD. ${ }^{164,170}$ Finally, acute renal failure can occur in the context of rhabdomyolysis as a severe consequence of malignant neuroleptic syndrome, as described later.

\section{Leucocytopenia, agranulocytosis, and thrombocytopenia}

Neutropenia, thrombocytopenia, and agranulocytosis can typically occur not only with CLO and phenothiazine but 
also with other antipsychotics such as RIS and QUE, in particular when the patient is on polypharmacotherapy with mood stabilizers. ${ }^{39,112}$ Case reports suggest that in patients with leukopenia (but not agranulocytosis), rechallenge with CLO is more often successful than not (70\%), especially under co-treatment with low-dose lithium. ${ }^{113}$

\section{Osteopenia, osteoporosis, and fractures}

Bone mineral density in patients with schizophrenia treated with antipsychotics is negatively related with age and positively with duration of antipsychotic treatment and illness duration, ${ }^{171}$ ultimately increasing the risk of osteoporosis. ${ }^{172-174}$ While preliminary data suggest an influence of elevated prolactin levels on bone turnover markers in schizophrenia treated with antipsychotics, ${ }^{175}$ suggesting that prolactinraising drugs should reduce bone mineral density, ${ }^{171}$ more studies are needed to better determine the precise mechanisms underlying the effect of antipsychotics on bone metabolism, as per an SR. ${ }^{176}$ Alongside with CVD, fractures explained part of the higher mortality with FGAs compared with SGAs in the elderly. ${ }^{121}$ However, fractures have been reported with all antipsychotics in patients with schizophrenia ${ }^{177}$ according to an SR. Osteopenia, osteoporosis, and fractures should be of particular concern in females during perimenopause when the risk for osteoporosis is elevated.

\section{Falls}

Considering that patients treated with antipsychotics have an increased risk for impaired bone metabolism for a number of reasons, including reduced physical activity and reduced sun exposure, falls due to side effects of AP can result in an increased risk of fractures, in particular within the first 30 days of treatment. ${ }^{178}$ However, in elderly patients, antipsychotics seem to be associated with a lower risk of falls than either antidepressants ${ }^{179}$ or benzodiazepines in the first 24 hours after the first administration. ${ }^{180}$ It remains difficult to establish whether the risk for falls with AP is due to sedation, visual impairment, hypotension, or motor side effects, but most likely a multi-factorial model can best explain the increased risk. Data are lacking about the incidence of falls in adults with schizophrenia and BD, although it is known that this group is at an increased risk of fall-related fractures. ${ }^{177}$

\section{Binge eating, pathological gambling, and impulse control disorders}

Binge eating is linked to receptor affinity to histaminergic receptors and is frequently observed with the prescription of OLA and CLO according to an RCT. ${ }^{181}$ Because of its partial agonist effect on dopamine receptors, ARI may increase the risk of impulse control disorder, hypersexuality, compulsive shopping, and pathological gambling according to preliminary case report data and one epidemiological study. ${ }^{182-184}$ Nevertheless, ARI usually has a net effect of dopamine antagonism, shown by worsening instead of improvement in motor symptoms in patients with Parkinson's disease. ${ }^{185}$ Hence, until more conclusive data exist and although the case reports may be related to symptoms of the disorders for which ARI was prescribed (as also indicated in the US Food and Drug Administration label of ARI), the risk for pathological gambling should be assessed when prescribing ARI to impulsive young patients with a history of substance abuse and to those with a high novelty-seeking profile. ${ }^{186}$

\section{Tobacco use}

Smoking is frequently a comorbidity in SMI, ${ }^{143}$ but antipsychotic treatment does not seem to increase the risk of smoking. Actually, both typical antipsychotics and CLO have been shown to increase the odds of smoking cessation in patients with schizophrenia. ${ }^{187,188}$ However, tobacco smoke increases the metabolism of several psychotropic medications through inducing enzymes in the cytochrome P450 system, CYP1A2 in particular. Thus, the pharmacokinetics of OLA, and CLO are influenced in clinically relevant ways by smoking habits, in that smoking can decrease circulating drug levels, with a required increase of drug dose by up to $50 \%{ }^{189}$ and risk of overdose upon smoking cessation. The cognitive-enhancing properties of pulsatile nicotine delivery may constitute self-treatment by patients with SMI in an attempt to improve cognitive function, impaired due to both the disease and its treatment. ${ }^{190}$

\section{Sexual and reproductive system dysfunction}

Sexual dysfunction is frequent during antipsychotic treatment and can be due to several factors, including co-treatment with two dopamine D2 antagonists, ${ }^{191}$ long duration of illness, and TD in schizophrenia. ${ }^{192}$ Hyperprolactinemia can cause sexual and reproductive system dysfunction, including decreased libido, erectile dysfunction, and anorgasmia, as well as reproductive system dysfunction, such as gynecomastia, galactorrhea, and oligo- or amenorrhea in women. All antipsychotics raise prolactin levels. AMI, RIS, and PALI do it the most. ${ }^{193-195}$ Conversely, drugs with a high $\alpha$-adrenergic antagonism can induce priapism ${ }^{196,197}$ and retrograde ejaculation, which may be disturbing for patients prone to delusions. ${ }^{198,199}$ It should also be considered that drugs with a high sedative profile may indirectly diminish sexual arousal and desire. ${ }^{199}$ Restricted comparative data 
limit conclusions about the relative ease with which different compounds affect sexual function.

\section{Endocrine diseases (diabetes ketoacidosis, hypothyroidism, and hyponatremia)}

Although no relevant clinical studies are available, diabetic ketoacidosis is frequently reported in case reports of patients taking antipsychotics, in particular OLA, CLO, and RIS. ${ }^{200,201}$

Hypothyroidism can occur with QUE, ARI, RIS, or OLA, in patients treated for $\mathrm{BD}$ in a large cohort. However, the frequency of hypothyroidism with SGAs is lower than with lithium. ${ }^{202}$ While there are case reports of QUE being associated with thyroid dysfunction, ${ }^{203}$ no clinically relevant risk of thyroid disturbance has been described in association with antipsychotics.

Hyponatremia risk appears to be increased with antipsychotic treatment and may be underestimated when several hyponatremia-inducing drugs are prescribed together, as reported in a large observational study. ${ }^{204}$ However, no solid literature provides comparative data for different compounds, and no sodium monitoring is recommended when antipsychotics are started. In addition, hyponatremia may be related to polydipsia, a clinical feature often associated with schizophrenia. ${ }^{205}$

\section{Hyperprolactinemia and prolactinoma}

The degree of hyperprolactinemia depends on the $\mathrm{D}_{2}$ receptor occupancy ${ }^{206}$ and on the antagonist properties of the antipsychotics. ${ }^{207}$ Thus, antipsychotics with a strong $\mathrm{D}_{2}$ affinity and antagonist pharmacodynamic properties increase prolactin serum levels the most, namely, AMI, HAL, PALI, and RIS. ${ }^{28,208}$ Moderate hyperprolactinemia has been described with SER, LUR, and ZIP; mild hyperprolactinemia has been described with ILO, CPZ, OLA, and ASE; and no hyperprolactinemia has been seen with the use of QUE and CLO. ${ }^{28,209}$ On the contrary, partial D2 agonists, such as ARI, BRE, and CAR, can lower prolactin levels, even below drug-free baseline, and adjunctive ARI has been shown to decrease hyperprolactinemia associated with other antipsychotics. ${ }^{28,209-211}$ Several cases have been reported describing antipsychotic use and prolactinoma, ${ }^{212}$ in particular in cases using $\mathrm{AMI}^{213,214}$ or RIS. ${ }^{215-217}$ However, no solid data are available, and thus, no conclusions can be drawn on the association of antipsychotics and prolactinoma. ${ }^{218}$

\section{Breast and cervical cancers}

Patients with SMI have lifestyle-related risk factors for cancer (smoking, caffeine intake, alcohol, lack of exercise) and often undergo less medical screening (for breast and cervical cancers for instance) than the general population. ${ }^{219,220}$ These factors could at least partially explain the higher cancer mortality rates, ${ }^{221}$ in particular for respiratory tumors, ${ }^{222}$ in patients with SMI, despite some evidence that suggests lower overall cancer rates. ${ }^{223}$ One mechanism that could contribute to an increased risk of tumorigenesis is antipsychoticrelated hyperprolactinemia (for breast and prostate cancers). However, in two recent reviews, no causal linkage has been demonstrated between cervical and breast cancers and antipsychotics. ${ }^{224,225}$ Moreover, comparative data from a large, national representative dataset have shown that RIS does not confer a higher risk of breast cancer compared to other antipsychotics, either FGAs or SGAs, while controlling to some degree for illness and behavior-related risk factors in individuals receiving antipsychotics. ${ }^{226}$ Thus, no conclusive evidence supports an increased risk of cancer in relation to the use of antipsychotics in schizophrenia or BD. ${ }^{227}$

\section{Neuroleptic malignant syndrome}

Neuroleptic malignant syndrome (NMS) is characterized by hyperthermia, rigidity, elevated creatinine phosphokinase (CPK) more than four times of the upper limit (and up to myoglobinuria), changes in mental status, and autonomic dysregulation..$^{204,228}$

While the exact incidence of NMS is unclear, ${ }^{229}$ it has potentially life-threatening consequences. NMS can occur with both FGAs and SGAs, in particular with the typical antipsychotics flupentixol, HAL, fluphenazine, thioridazine, $\mathrm{CPZ}$, trifluoperazine, LOX, periciazine, methotrimeprazine, prochlorperazine, and zuclopenthixol, as well as with CLO, OLA, RIS, QUE, ARI, PALI, ASE, and ZIP. ${ }^{230}$ While no clear consensus exists, ${ }^{230} \mathrm{SGA}$-associated NMS seems to be of lower frequency, severity, duration, and lethality than NMS associated with FGAs. ${ }^{231,232}$ CLO may have the highest risk of NMS among SGAs, ${ }^{230}$ although patient-related factors may also play a role. Beyond specific pharmacologic compounds, several environmental factors can increase the risk of NMS, including the use of high doses, parenteral administration, polypharmacotherapy, physical restraint, dehydration, high temperature, older age and multiple medical comorbidities, previous history of NMS, family history of catatonia, and muscle channelopathy. ${ }^{230}$

\section{Mortality}

Several studies report that higher antipsychotic dosage and polypharmacy increase the risk of mortality in patients with schizophrenia, ${ }^{233}$ with a higher risk for FGAs compared to SGAs. ${ }^{121}$ Death is mediated by pneumonia, CVD, hip fracture, and cardiac arrhythmias, among other dysfunctions. ${ }^{121,137}$ 


\section{Withdrawal and rebound syndromes}

Withdrawal and rebound syndromes related to antipsychotic treatment depend on the pharmacokinetic and pharmacodynamic profiles of the discontinued pre-switch antipsychotics and of the post-switch antipsychotics if withdrawal symptoms occur during antipsychotic switching. While the pharmacokinetic profile influences the timing of the occurrence of such syndromes, pharmacodynamics determines their symptomatic presentation..$^{35}$ Withdrawal or rebound syndromes are central and peripheral phenomena induced by the sudden reversal of receptor blockade when the pre-switch medication is discontinued too quickly and the post-switch drug is a comparatively less efficient receptor antagonist.

One of the factors associated with withdrawal reactions is plasma half-life. Generally, it takes approximately five times a compound's half-life for it to be completely eliminated from plasma; such pharmacokinetic parameters should be taken into account when stopping a treatment or switching to a different antipsychotic. The antipsychotics with the shortest half-life are QUE immediate release and ZIP ( $<12$ hours). ILO, AMI, CLO, HAL, and PER have a relatively short half-life (12-24 hours), while RIS/PALI and OLA have a moderately short one (20-36 hours). ARI, BRE, CAR, and SER have the longest half-lives (50-100 hours). The most important determinant of rebound is how long the drug attaches to the receptor; CLO for instance spends very little time at the receptor; OLA and QUE are the next shortest. Conversely, HAL attaches for a very long time..$^{234}$

From a clinical perspective, upon withdrawal from a drug, one should expect peripheral manifestations opposite to those that were initially blocked by the drug. For example, one would expect diarrhea, sweating, nausea, vomiting, and hypotension when a medication with a strong anticholinergic activity is abruptly withdrawn or tachycardia and hypertension when an agent with potent alphal blocking potential is rapidly stopped. The rebound syndrome is caused by the exposure of a previously blocked and thus upregulated receptor system to its natural ligand. ${ }^{35}$ Typically, histaminergic rebound includes anxiety, agitation, insomnia, restlessness, and EPS; cholinergic rebound is marked by agitation, confusion, and EPS; and dopaminergic rebound can manifest as increased psychotic symptoms, mania, agitation, aggression, akathisia, or dyskinesia. ${ }^{35}$ Hence, particular attention should be paid when switching from antipsychotics with strong antihistaminergic, anticholinergic, and/or antidopaminergic properties to those with lower affinities for these receptors. In addition to such "pharmacodynamic rebound" syndromes, "pharmacokinetic rebound" can occur when the post-switch antipsychotic is inadequately dosed or has a much longer half-life than the pre-switch antipsychotic. In this scenario, unless cross-titration is used, and depending on the relative half-lives of the discontinued and the new drug, the patient can suffer from temporary underdosing or overdosing. ${ }^{35,235}$

\section{Pregnancy and breastfeeding}

During pregnancy, OLA, CLO, and QUE, alongside with other antipsychotics, may be expected to increase the risk of gestational diabetes, hypertension, thromboembolism, or congenital malformations. However, evidence on the safety of these agents during pregnancy remains limited and conflicting. While an SR suggested the use of FGAs instead of SGAs during pregnancy, due to the fact that these latter agents may increase the risk of gestational diabetes and large-for-gestational-age babies, ${ }^{236}$ more recent large-scale observational studies do not confirm such a concern in terms of mother and newborn safety; these studies did, on the other hand, verify an increased risk for perinatal complications and low birth weight with FGAs. ${ }^{237,238} \mathrm{~A}$ recent expert panel recommended the use of OLA during pregnancy due to the large amount of safety data; ${ }^{239}$ the same panel suggested that QUE and RIS were also safe for use during pregnancy. ${ }^{239}$ However, a recent large database study found that RIS use was associated with a small risk of cardiac and overall malformations even after adjustment to potential confounders. ${ }^{240}$

During breastfeeding, QUE, OLA, and ARI can be used; the relative infant doses (RIDs) for these agents are low $(<2 \%){ }^{239}$ RIS may be used under medical supervision, while AMI and CLO should be avoided. ${ }^{195}$ Safety in lactation depends on the properties of the drug that determine its ease of passage into breast milk.

\section{Sleepwalking and other sleep disturbances}

Several case reports have described sleepwalking or other sleep disturbances (such as daytime sedation and sleep apnea described earlier) in association with antipsychotics administration; however, it remains debatable whether antipsychotics contribute to the risk of sleep disturbances or may, in fact, help to reverse them. ${ }^{241}$ Overall, no definitive evidence is available on this matter.

\section{Hypothermia}

Increasingly, sporadic cases of hypothermia have been described when antipsychotics were administered; while a precise mechanism, namely, 5HT2 antagonism, has been 
suggested, large studies with consistent (comparative) data are still lacking. ${ }^{242}$

\section{Discussion}

When assessing a medication, both efficacy and tolerability are equally important, not only because adverse effects can reduce subjective well-being and adherence but also because adverse effects can adversely affect treatment outcomes. ${ }^{50,243}$ Notwithstanding the fact that differences in efficacy among antipsychotics are relatively small and difficult to predict (with the one exception of CLO, which has shown a clear advantage over other agents for treatment-resistant schizophrenia), the ability to accurately predict differences in treatment-emergent adverse effects is critical. Such effects depend, at least in part, on distinct pharmacodynamic profiles of the various drugs. ${ }^{28,39,244}$ Although the differentiation of antipsychotics into FGAs and SGAs is based on history and is overly simplistic, obscuring the different profiles of individual antipsychotics within each class that markedly diverge in their safety and tolerability profiles, this classification is still used and has some heuristic value. According to our review, generally, FGA-related adverse effects that affect symptomatic and functional outcomes include neuromotor disorders as well as the possibility of worsening negative symptoms, social withdrawal, and cognitive dysfunction. These effects may explain the lower adherence to FGAs compared to SGAs. However, the use of SGAs often leads to serious adverse cardiometabolic effects, individual agents carrying a different propensity for weight gain and metabolic side effects. Importantly, the use of SGAs appears to be associated with less cognitive impairment than that of FGAs. With respect to management, treatment-emergent effects related to the use of FGAs, such as TD, are challenging to treat but the more common EPS respond well to anticholinergic medication. Sometimes, however, this is at the expense of worsening cognitive function. SGA-induced "metabolic" comorbidity can theoretically be prevented or reduced through the adoption of a multidisciplinary approach of active monitoring plus careful attention to diet and activity level. However, diet alone does not prevent SGA-induced weight gain; although weight loss has been demonstrated, ${ }^{245,246}$ no evidence of a positive dietary modulation of SGA-induced metabolic effects has thus far been evidenced. ${ }^{247}$ A metaanalysis of physical exercise-based intervention for both BD and schizophrenia showed an increase in the physical activity of patients but no clear beneficial effects on physical parameters. ${ }^{248}$ A meta-analysis on mixed dietary and physical exercise interventions found very small positive effects (eg, a BMI reduction of 1 point). It is possible, however, that high heterogeneity and a relatively low quality of trials may have biased the results. ${ }^{249}$ Nevertheless, methodologically the best and largest individual RCT on this topic showed no real benefit of behavioral interventions on overall metabolic parameters. ${ }^{250}$

Important to keep in mind for the treatment of schizophrenia is that although FGAs and SGAs are equally effective in treating positive symptoms, negative and cognitive symptoms may be aggravated by FGAs. ${ }^{55,251}$ In the past, outcome measures were predominantly based on symptom reduction, but today, improvements in quality of life and overall functional "recovery" constitute "real-world" therapeutic aims. Subjective measures are what matters most for current gold standards of outcome, and both negative and cognitive symptoms are more relevant here than the presence or absence of positive psychotic symptoms. For BD, the depressive polarity is most common ${ }^{252}$ and is also associated with a worse global outcome and with more functional impairment than is the presence of manic episodes. ${ }^{253}$ The evidence for antipsychotic efficacy in the treatment of depression in BD is sparse, except for positive reports on QUE, LUR, OLA, and CAR. ${ }^{254}$ There is strong evidence, however, for most SGAs of efficacy in the treatment of mania and manic-predominant polarity patients. ${ }^{255,256}$ The clinical challenge in the management of mania remains, nonetheless, because of poor treatment adherence and symptom control rooted in poor insight and comorbid substance abuse. . $57,258^{2}$

Relying on the 50 years old yet still currently applicable theoretical framework of "behavioral toxicity", ${ }^{47,48}$ we conclude that SGAs have broadened the range of therapeutic options in the treatment of schizophrenia and $\mathrm{BD}$, rapidly gaining first-line rank, especially in international clinical guidelines for the evidence-based, long-term treatment of both schizophrenia and BD. ${ }^{170,259-261}$ The broad division of antipsychotics into FGAs and SGAs, although flawed, allows for individualized treatment choices that balance clinical and tolerability concerns. These choices, to date, are mostly limited to careful clinical observation and assessment. Although modern, neurobiologically based instruments - such as pharmacogenetic tests or biomarker-based decision making - have been developed, they are only, as yet, partially implemented. They currently show guarded promise for optimal selection of individually tailored antipsychotic agents. ${ }^{262,263}$

The limitation of this review is a dearth of information on newer compounds, such as BRE, LUR, and CAR. 
Furthermore, information about long-term effects is limited since most trials are of short duration. Data on the incidence of potentially serious adverse effects (NMS, agranulocytosis, diabetic ketoacidosis, pathological gambling, and pancreatitis) and on long-term side effects (eg, type 2 diabetes, TD, stroke, AMI, cancer, osteoporosis) remain inconclusive. Long-term effects on fetuses exposed in utero to these drugs remain unknown.

Using a framework that balances efficacy against target symptoms with the potential for behavioral toxicity, this review brings together what is currently known about the clinical use of antipsychotics. Methodologically improved clinical trials and large, prospective, longitudinal populationbased observational studies will, in the future, fill the gaps described earlier and provide further evidence on the safety and tolerability of antipsychotic medications.

\section{Acknowledgment}

This review was supported by Comisión Nacional de Investigación Científica y Tecnológica, Fondo Nacional de Investigación y Desarrollo en Salud ID: SA15I10058 (to JU); Interdisciplinary Research Program PIA ACT1414 (to JU); and Fondo Nacional de Desarrollo Científico y Tecnológico ID: 1160736 (to JU).

\section{Disclosure}

AM has received Continuing Medical Education-related honoraria or consulting fees from Adamed, AstraZeneca, Bristol-Myers-Squibb, Janssen, Lundbeck, and Otsuka.

IP has received CME-related honoraria or consulting fees from Adamed, Janssen-Cilag, and Lundbeck.

EV has received grants and served as a consultant, advisor, or CME speaker for the following entities: AB-Biotics, Allergen, AstraZeneca, Bristol-Myers-Squibb, Ferrer, Forest Research Institute, Gedeon Richter, Glaxo-Smith-Kline, Janssen, Lundbeck, Otsuka, Pfizer, Roche, Sanofi-Aventis, Servier, Shire, Sunovion, Takeda, Telefonica, the Brain and Behaviour Foundation, the Spanish Ministry of Science and Innovation (Centro de Investigación Biomédica en Red de Salud Mental), the Seventh European Framework Programme (European Network of Bipolar Research Expert Centres), and the Stanley Medical Research Institute.

CUC has received grant or research support from the National Institute of Mental Health, the Patient-Centered Outcomes Research Institute, the American Academy of Child and Adolescent Psychiatry, The Bendheim Foundation, Takeda, and the Thrasher Foundation. He has served as a member of advisory boards/the Data Safety
Monitoring Boards for Alkermes, Forum, IntraCellular Therapies, Lundbeck, Otsuka, Pfizer, and Sunovion. He has served as a consultant to Alkermes, the Gerson Lehrman Group, IntraCellular Therapies, Janssen/Johnson and Johnson, Lundbeck, Medscape, Otsuka, Pfizer, ProPhase, Sunovion, Supernus, and Takeda. He has presented expert testimony for Bristol-Myers Squibb, Janssen, and Otsuka. He has received honorarium from Medscape. He has received travel expenses from Janssen/Johnson and Johnson, Lundbeck, Otsuka, Pfizer, ProPhase, Sunovion, and Takeda.

MS, JU, NV, MF, BS, FM, MVS, and AFC report no conflicts of interest in this work.

\section{References}

1. Gilmer T, Henwood B, McGovern N, Hurst S, Burgdorf J, InnesGomberg D. Health outcomes and costs associated with the provision of culturally competent services for underrepresented ethnic populations with severe mental illness. Adm Policy Ment Health. 2017. Epub 2017 Jan 3.

2. Zhai J, Guo X, Chen M, Zhao J, Su Z. An investigation of economic costs of schizophrenia in two areas of China. Int J Ment Health Syst. 2013;7(1):26.

3. De Hert M, Thys E, Boydens J, et al. Health care expenditure on schizophrenia patients in Belgium. Schizophr Bull. 1998;24(4):519-527.

4. Laursen TM, Musliner KL, Benros ME, Vestergaard M, Munk-Olsen T. Mortality and life expectancy in persons with severe unipolar depression. J Affect Disord. 2016;193:203-207.

5. Laursen TM. Life expectancy among persons with schizophrenia or bipolar affective disorder. Schizophr Res. 2011;131(1-3):101-104.

6. Kishimoto T, Agarwal V, Kishi T, Leucht S, Kane JM, Correll CU. Relapse prevention in schizophrenia: a systematic review and metaanalysis of second-generation antipsychotics versus first-generation antipsychotics. Mol Psychiatry. 2013;18(1):53-66.

7. Ifteni P, Moga MA, Burtea V, Correll CU. Schizophrenia relapse after stopping olanzapine treatment during pregnancy: a case report. Ther Clin Risk Manag. 2014;10:901-904.

8. Bortolato B, Carvalho AF, McIntyre RS. Cognitive dysfunction in major depressive disorder: a state-of-the-art clinical review. CNS Neurol Disord Drug Targets. 2014;13(10):1804-1818.

9. Bortolato B, Miskowiak KW, Kohler CA, Vieta E, Carvalho AF. Cognitive dysfunction in bipolar disorder and schizophrenia: a systematic review of meta-analyses. Neuropsychiatr Dis Treat. 2015;11: 3111-3125.

10. Bortolato B, Miskowiak KW, Kohler CA, et al. Cognitive remission: a novel objective for the treatment of major depression? BMC Med. 2016;14:9.

11. Madre M, Canales-Rodriguez EJ, Ortiz-Gil J, et al. Neuropsychological and neuroimaging underpinnings of schizoaffective disorder: a systematic review. Acta Psychiatr Scand. 2016;134(1):16-30.

12. Bora E, Akdede BB, Alptekin K. The relationship between cognitive impairment in schizophrenia and metabolic syndrome: a systematic review and meta-analysis. Psychol Med. 2017;47(6):1030-1040.

13. Sole B, Vieta E, Martinez-Aran A. Thinking ahead: executive dysfunction in bipolar disorder. Eur Neuropsychopharmacol. 2016;26(8): $1348-1349$.

14. Leucht S, Tardy M, Komossa K, et al. Antipsychotic drugs versus placebo for relapse prevention in schizophrenia: a systematic review and meta-analysis. Lancet. 2012;379(9831):2063-2071.

15. Zhou X, Keitner GI, Qin B, et al. Atypical antipsychotic augmentation for treatment-resistant depression: a systematic review and network meta-analysis. Int J Neuropsychopharmacol. 2015;18(11):yv060. 
16. Fountoulakis KN, Yatham L, Grunze H, et al. The International College of Neuro-Psychopharmacology (CINP) treatment guidelines for bipolar disorder in adults (CINP-BD-2017), part 2: review, grading of the evidence, and a precise algorithm. Int J Neuropsychopharmacol. 2017;20(2):121-179.

17. Taylor DM, Cornelius V, Smith L, Young AH. Comparative efficacy and acceptability of drug treatments for bipolar depression: a multiple-treatments meta-analysis. Acta Psychiatr Scand. 2014;130(6): 452-469.

18. Yildiz A, Nikodem M, Vieta E, Correll CU, Baldessarini RJ. A network meta-analysis on comparative efficacy and all-cause discontinuation of antimanic treatments in acute bipolar mania. Psychol Med. 2015; 45(2):299-317.

19. Greenblatt HK, Greenblatt DJ. Use of antipsychotics for the treatment of behavioral symptoms of dementia. J Clin Pharmacol. 2016; 56(9):1048-1057.

20. Farlow MR, Shamliyan TA. Benefits and harms of atypical antipsychotics for agitation in adults with dementia. Eur Neuropsychopharmacol 2017;27(3):217-231

21. Ma H, Huang Y, Cong Z, et al. The efficacy and safety of atypical antipsychotics for the treatment of dementia: a meta-analysis of randomized placebo-controlled trials. J Alzheimers Dis. 2014;42(3):915-937.

22. Maher AR, Maglione M, Bagley S, et al. Efficacy and comparative effectiveness of atypical antipsychotic medications for off-label uses in adults: a systematic review and meta-analysis. JAMA. 2011;306(12): 1359-1369.

23. Altamura AC, Dragogna F. Should the term 'antipsychotic' be changed to 'multidimensional stabiliser' in bipolar disorder? Towards a new denomination for 'atypical antipsychotics'. Aust NZJ Psychiatry. 2013 47(8):707-709.

24. Delay J, Deniker P, Ropert R. Quatre années d'expérience de la chlorpromazine dans le traitement des psychoses [Four years of experience with chlorpromazine in therapy of psychoses]. Presse Med. 1956; 64(22):493-496.

25. Brill NQ, Koegler RR, Epstein LJ, Forgy EW. Controlled study of psychiatric outpatient treatment. Arch Gen Psychiatry. 1964;10:581-595.

26. Buoli M, Kahn RS, Serati M, Altamura AC, Cahn W. Haloperidol versus second-generation antipsychotics in the long-term treatment of schizophrenia. Hum Psychopharmacol. 2016;31(4):325-331.

27. Altamura AC, Buoli M, Mauri MC. Haloperidol versus secondgeneration antipsychotics in the long-term treatment of schizophrenia: a 4-year follow-up naturalistic study. J Clin Psychopharmacol. 2011; 31(5):661-663.

28. Leucht S, Cipriani A, Spineli L, et al. Comparative efficacy and tolerability of 15 antipsychotic drugs in schizophrenia: a multiple-treatments meta-analysis. Lancet. 2013;382(9896):951-962.

29. Hippius H. A historical perspective of clozapine. J Clin Psychiatry. 1999;60(suppl 12):22-23.

30. Gerlach J, Koppelhus P, Helweg E, Monrad A. Clozapine and haloperidol in a single-blind cross-over trial: therapeutic and biochemical aspects in the treatment of schizophrenia. Acta Psychiatr Scand. 1974; 50(4):410-424.

31. Voruganti LN, Heslegrave RJ, Awad AG. Quality of life measurement during antipsychotic drug therapy of schizophrenia. J Psychiatry Neurosci. 1997;22(4):267-274.

32. Mortimer AM, Al-Agib AO. Quality of life in schizophrenia on conventional versus atypical antipsychotic medication: a comparative cross-sectional study. Int J Soc Psychiatry. 2007;53(2):99-107.

33. Li Q, Xiang YT, Su YA, et al. Antipsychotic polypharmacy in schizophrenia patients in China and its association with treatment satisfaction and quality of life: findings of the third national survey on use of psychotropic medications in China. Aust N Z J Psychiatry. 2015;49(2):129-136.

34. Rauly-Lestienne I, Boutet-Robinet E, Ailhaud MC, Newman-Tancredi A, Cussac D. Differential profile of typical, atypical and third generation antipsychotics at human 5-HT7a receptors coupled to adenylyl cyclase: detection of agonist and inverse agonist properties. Naunyn Schmiedebergs Arch Pharmacol. 2007;376(1-2):93-105.
35. Correll CU. From receptor pharmacology to improved outcomes: individualising the selection, dosing, and switching of antipsychotics. Eur Psychiatry. 2010;25(suppl 2):S12-S21.

36. Vancampfort D, Stubbs B, Mitchell AJ, et al. Risk of metabolic syndrome and its components in people with schizophrenia and related psychotic disorders, bipolar disorder and major depressive disorder: a systematic review and meta-analysis. World Psychiatry. 2015;14(3): 339-347.

37. Kagal UA, Torgal SS, Patil NM, Malleshappa A. Prevalence of the metabolic syndrome in schizophrenic patients receiving second-generation antipsychotic agents - a cross-sectional study. J Pharm Pract. 2012; 25(3):368-373.

38. Correll CU, Frederickson AM, Kane JM, Manu P. Does antipsychotic polypharmacy increase the risk for metabolic syndrome? Schizophr Res. 2007;89(1-3):91-100.

39. Correll CU, Detraux J, De Lepeleire J, De Hert M. Effects of antipsychotics, antidepressants and mood stabilizers on risk for physical diseases in people with schizophrenia, depression and bipolar disorder. World Psychiatry. 2015;14(2):119-136.

40. Zdanys KF, Carvalho AF, Tampi RR, Steffens DC. The treatment of behavioral and psychological symptoms of dementia: weighing benefits and risks. Curr Alzheimer Res. 2016;13(10):1124-1133.

41. Deng C. Effects of antipsychotic medications on appetite, weight, and insulin resistance. Endocrinol Metab Clin North Am. 2013;42(3): 545-563.

42. Vancampfort D, Correll CU, Galling B, et al. Diabetes mellitus in people with schizophrenia, bipolar disorder and major depressive disorder: a systematic review and large scale meta-analysis. World Psychiatry. 2016;15(2):166-174.

43. Hill M, Crumlish N, Whitty P, et al. Nonadherence to medication four years after a first episode of psychosis and associated risk factors. Psychiatr Serv. 2010;61(2):189-192.

44. Pogge DL, Singer MB, Harvey PD. Rates and predictors of adherence with atypical antipsychotic medication: a follow-up study of adolescent inpatients. J Child Adolesc Psychopharmacol. 2005;15(6): 901-912.

45. Karow A, Czekalla J, Dittmann RW, et al. Association of subjective well-being, symptoms, and side effects with compliance after 12 months of treatment in schizophrenia. J Clin Psychiatry. 2007;68(1): 75-80.

46. Morken G, Widen JH, Grawe RW. Non-adherence to antipsychotic medication, relapse and rehospitalisation in recent-onset schizophrenia. BMC Psychiatry. 2008;8:32.

47. DiMascio A, Shader RI, Harmatz GS. Behavioral toxicity of psychotropic drugs. V. Effects on gross behavior patterns. Conn Med. 1969;33(4): 279-281.

48. DiMascio A, Shader RI. Behavioral toxicity of psychotropic drugs. I. Definition. II. Toxic effects on psychomotor functions. Conn Med. 1968;32(8):617-620.

49. DiMascio A, Giller DR, Shader RI. Behavioral toxicity of psychotropic drugs. 3. Effects on perceptual and cognitive functions. IV. Effects on emotional (mood) states. Conn Med. 1968;32(10):771-775.

50. Fava GA, Cosci F, Offidani E, Guidi J. Behavioral toxicity revisited: iatrogenic comorbidity in psychiatric evaluation and treatment. J Clin Psychopharmacol. 2016;36(6):550-553.

51. Fava GA, Tossani E, Bech P, et al. Emerging clinical trends and perspectives on comorbid patterns of mental disorders in research. Int $J$ Methods Psychiatr Res. 2014;23(suppl 1):92-101.

52. Riedel M, Schmitz M, Ostergaard PK, et al. Comparison of the effects of quetiapine extended-release and quetiapine immediate-release on cognitive performance, sedation and patient satisfaction in patients with schizophrenia: a randomised, double-blind, crossover study (eXtRa). Schizophr Res. 2015;162(1-3):162-168.

53. Citrome L. Activating and sedating adverse effects of second-generation antipsychotics in the treatment of schizophrenia and major depressive disorder: absolute risk increase and number needed to harm. J Clin Psychopharmacol. 2017;37(2):138-147. 
54. Meduri M, Gregoraci G, Baglivo V, Balestrieri M, Isola M, Brambilla P. A meta-analysis of efficacy and safety of aripiprazole in adult and pediatric bipolar disorder in randomized controlled trials and observational studies. J Affect Disord. 2016;191:187-208.

55. Zhang JP, Gallego JA, Robinson DG, Malhotra AK, Kane JM, Correll CU. Efficacy and safety of individual second-generation vs. first-generation antipsychotics in first-episode psychosis: a systematic review and meta-analysis. Int $J$ Neuropsychopharmacol. 2013;16(6): 1205-1218.

56. Babin SL, Hood AJ, Wassef AA, Williams NG, Patel SS, Sereno AB. Effects of haloperidol on cognition in schizophrenia patients depend on baseline performance: a saccadic eye movement study. Prog Neuropsychopharmacol Biol Psychiatry. 2011;35(7):1753-1764.

57. Takeuchi H, Suzuki T, Remington G, et al. Effects of risperidone and olanzapine dose reduction on cognitive function in stable patients with schizophrenia: an open-label, randomized, controlled, pilot study. Schizophr Bull. 2013;39(5):993-998.

58. Sakurai H, Bies RR, Stroup ST, et al. Dopamine D2 receptor occupancy and cognition in schizophrenia: analysis of the CATIE data. Schizophr Bull. 2013;39(3):564-574.

59. Trampush JW, Lencz T, DeRosse P, et al. Relationship of cognition to clinical response in first-episode schizophrenia spectrum disorders. Schizophr Bull. 2015;41(6):1237-1247.

60. Robles O, Zabala A, Bombin I, et al. Cognitive efficacy of quetiapine and olanzapine in early-onset first-episode psychosis. Schizophr Bull. 2011;37(2):405-415.

61. Komossa K, Rummel-Kluge C, Schwarz S, et al. Risperidone versus other atypical antipsychotics for schizophrenia. Cochrane Database Syst Rev. 2011;(1).

62. Asenjo Lobos C, Komossa K, Rummel-Kluge C, et al. Clozapine versus other atypical antipsychotics for schizophrenia. Cochrane Database Syst Rev. 2010;(11).

63. Komossa K, Rummel-Kluge C, Hunger H, et al. Olanzapine versus other atypical antipsychotics for schizophrenia. Cochrane Database Syst Rev. 2010;(3).

64. Zhou Z, Zhu H, Chen L. Effect of aripiprazole on mismatch negativity (MMN) in schizophrenia. PLoS One. 2013;8(1):e52186.

65. Citrome L, Ota A, Nagamizu K, Perry P, Weiller E, Baker RA. The effect of brexpiprazole (OPC-34712) and aripiprazole in adult patients with acute schizophrenia: results from a randomized, exploratory study. Int Clin Psychopharmacol. 2016;31(4):192-201.

66. Khanna P, Suo T, Komossa K, et al. Aripiprazole versus other atypical antipsychotics for schizophrenia. Cochrane Database Syst Rev. 2014;(1).

67. Manu P, Dima L, Shulman M, Vancampfort D, De Hert M, Correll CU. Weight gain and obesity in schizophrenia: epidemiology, pathobiology, and management. Acta Psychiatr Scand. 2015;132(2):97-108.

68. De Hert M, Yu W, Detraux J, Sweers K, van Winkel R, Correll CU. Body weight and metabolic adverse effects of asenapine, iloperidone, lurasidone and paliperidone in the treatment of schizophrenia and bipolar disorder: a systematic review and exploratory meta-analysis. CNS Drugs. 2012;26(9):733-759.

69. De Hert M, Detraux J, van Winkel R, Yu W, Correll CU. Metabolic and cardiovascular adverse effects associated with antipsychotic drugs. Nat Rev Endocrinol. 2011;8(2):114-126.

70. Robinson DG, Gallego JA, John M, et al. A randomized comparison of aripiprazole and risperidone for the acute treatment of first-episode schizophrenia and related disorders: 3-month outcomes. Schizophr Bull. 2015;41(6):1227-1236.

71. Lakka HM, Laaksonen DE, Lakka TA, et al. The metabolic syndrome and total and cardiovascular disease mortality in middle-aged men. JAMA. 2002;288(21):2709-2716.

72. Maayan L, Correll CU. Management of antipsychotic-related weight gain. Expert Rev Neurother. 2010;10(7):1175-1200.

73. Stubbs B, Williams J, Gaughran F, Craig T. How sedentary are people with psychosis? A systematic review and meta-analysis. Schizophr Res. 2016;171(1-3):103-109.
74. Misawa F, Shimizu K, Fujii Y, et al. Is antipsychotic polypharmacy associated with metabolic syndrome even after adjustment for lifestyle effects? A cross-sectional study. BMC Psychiatry. 2011:11:118.

75. Rummel-Kluge C, Komossa K, Schwarz S, et al. Second-generation antipsychotic drugs and extrapyramidal side effects: a systematic review and meta-analysis of head-to-head comparisons. Schizophr Bull. 2012;38(1):167-177.

76. Lao KS, He Y, Wong IC, Besag FM, Chan EW. Tolerability and safety profile of cariprazine in treating psychotic disorders, bipolar disorder and major depressive disorder: a systematic review with metaanalysis of randomized controlled trials. CNS Drugs. 2016;30(11): 1043-1054.

77. Gao K, Kemp DE, Ganocy SJ, Gajwani P, Xia G, Calabrese JR. Antipsychotic-induced extrapyramidal side effects in bipolar disorder and schizophrenia: a systematic review. J Clin Psychopharmacol. 2008;28(2):203-209.

78. Rapoport A, Stein D, Grinshpoon A, Elizur A. Akathisia and pseudoakathisia: clinical observations and accelerometric recordings. $J$ Clin Psychiatry. 1994;55(11):473-477.

79. Havaki-Kontaxaki BJ, Kontaxakis VP, Christodoulou GN. Prevalence and characteristics of patients with pseudoakathisia. Eur Neuropsychopharmacol. 2000;10(5):333-336.

80. Correll CU, Leucht S, Kane JM. Lower risk for tardive dyskinesia associated with second-generation antipsychotics: a systematic review of 1-year studies. Am J Psychiatry. 2004;161(3):414-425.

81. O'Brien A. Comparing the risk of tardive dyskinesia in older adults with first-generation and second-generation antipsychotics: a systematic review and meta-analysis. Int J Geriatr Psychiatry. 2016;31(7): 683-693.

82. Cavazzoni PA, Berg PH, Kryzhanovskaya LA, et al. Comparison of treatment-emergent extrapyramidal symptoms in patients with bipolar mania or schizophrenia during olanzapine clinical trials. J Clin Psychiatry. 2006;67(1):107-113.

83. Bobo WV, Shelton RC. Risperidone long-acting injectable (Risperdal Consta(R)) for maintenance treatment in patients with bipolar disorder. Expert Rev Neurother. 2010;10(11):1637-1658.

84. Ono S, Suzuki Y, Shindo M, et al. Improvement of tardive dyskinesia and dystonia associated with aripiprazole following a switch to quetiapine: case report and review of the literature. J Clin Pharm Ther. 2012;37(3):370-372.

85. Tiwari AK, Zai CC, Likhodi O, et al. Association study of cannabinoid receptor 1 (CNR1) gene in tardive dyskinesia. Pharmacogenomics $J$. 2012;12(3):260-266.

86. Fedorenko OY, Loonen AJ, Lang F, et al. Association study indicates a protective role of phosphatidylinositol-4-phosphate-5-kinase against tardive dyskinesia. Int J Neuropsychopharmacol. 2014;18(6).

87. Mas S, Gasso P, Lafuente A, et al. Pharmacogenetic study of antipsychotic induced acute extrapyramidal symptoms in a first episode psychosis cohort: role of dopamine, serotonin and glutamate candidate genes. Pharmacogenomics J. 2016;16(5):439-445.

88. Achalia RM, Chaturvedi SK, Desai G, Rao GN, Prakash O. Prevalence and risk factors associated with tardive dyskinesia among Indian patients with schizophrenia. Asian J Psychiatr. 2014;9:31-35.

89. Oosthuizen PP, Emsley RA, Maritz JS, Turner JA, Keyter N. Incidence of tardive dyskinesia in first-episode psychosis patients treated with low-dose haloperidol. J Clin Psychiatry. 2003;64(9):1075-1080.

90. Caligiuri MP, Lacro JP, Rockwell E, McAdams LA, Jeste DV. Incidence and risk factors for severe tardive dyskinesia in older patients. $\mathrm{Br} \mathrm{J}$ Psychiatry. 1997;171:148-153.

91. Bergen J, Kitchin R, Berry G. Predictors of the course of tardive dyskinesia in patients receiving neuroleptics. Biol Psychiatry. 1992;32(7): 580-594.

92. Woerner MG, Correll CU, Alvir JM, Greenwald B, Delman H, Kane JM. Incidence of tardive dyskinesia with risperidone or olanzapine in the elderly: results from a 2-year, prospective study in antipsychotic-naive patients. Neuropsychopharmacology. 2011;36(8): $1738-1746$ 
93. Lertxundi U, Hernandez R, Medrano J, Domingo-Echaburu S, Garcia M, Aguirre C. Antipsychotics and seizures: higher risk with atypicals? Seizure. 2013;22(2):141-143.

94. Haddad PM, Sharma SG. Adverse effects of atypical antipsychotics: differential risk and clinical implications. CNS Drugs. 2007;21(11): 911-936.

95. Wu CS, Wang SC, Yeh IJ, Liu SK. Comparative risk of seizure with use of first- and second-generation antipsychotics in patients with schizophrenia and mood disorders. J Clin Psychiatry. 2016;77(5):e573-e579.

96. Witkin JM, Levant B, Zapata A, Kaminski R, Gasior M. The dopamine D3/D2 agonist (+)-PD-128,907 [(R-(+)-trans-3,4a,10b-tetrahydro-4propyl-2H,5H-[1]benzopyrano[4,3-b]-1,4-oxazin -9-ol)] protects against acute and cocaine-kindled seizures in mice: further evidence for the involvement of D3 receptors. J Pharmacol Exp Ther. 2008;326(3): 930-938.

97. Blom MT, Cohen D, Seldenrijk A, et al. Brugada syndrome ECG is highly prevalent in schizophrenia. Circ Arrhythm Electrophysiol. 2014;7(3):384-391

98. Jensen KG, Juul K, Fink-Jensen A, Correll CU, Pagsberg AK. Corrected QT changes during antipsychotic treatment of children and adolescents: a systematic review and meta-analysis of clinical trials. $J$ Am Acad Child Adolesc Psychiatry. 2015;54(1):25-36.

99. Yang FD, Wang XQ, Liu XP, et al. Sex difference in QTc prolongation in chronic institutionalized patients with schizophrenia on long-term treatment with typical and atypical antipsychotics. Psychopharmacology (Berl). 2011;216(1):9-16.

100. Zhai D, Lang Y, Dong G, et al. QTc interval lengthening in firstepisode schizophrenia (FES) patients in the earliest stages of antipsychotic treatment. Schizophr Res. 2017;179:70-74.

101. Wu CS, Tsai YT, Tsai HJ. Antipsychotic drugs and the risk of ventricular arrhythmia and/or sudden cardiac death: a nation-wide casecrossover study. J Am Heart Assoc. 2015;4(2).

102. Linder JR, Sodhi SK, Haynes WG, Fiedorowicz JG. Effects of antipsychotic drugs on cardiovascular variability in participants with bipolar disorder. Hum Psychopharmacol. 2014;29(2):145-151.

103. Ebrahimzadeh E, Pooyan M, Bijar A. A novel approach to predict sudden cardiac death (SCD) using nonlinear and time-frequency analyses from HRV signals. PLoS One. 2014;9(2):e81896.

104. Citrome L. Brexpiprazole for schizophrenia and as adjunct for major depressive disorder: a systematic review of the efficacy and safety profile for this newly approved antipsychotic - what is the number needed to treat, number needed to harm and likelihood to be helped or harmed? Int J Clin Pract. 2015;69(9):978-997.

105. Potkin SG, Preskorn S, Hochfeld M, Meng X. A thorough QTc study of 3 doses of iloperidone including metabolic inhibition via CYP2D6 and/or CYP3A4 and a comparison to quetiapine and ziprasidone. J Clin Psychopharmacol. 2013;33(1):3-10.

106. Citrome L. Cariprazine for the treatment of schizophrenia: a review of this dopamine D3-preferring D3/D2 receptor partial agonist. Clin Schizophr Relat Psychoses. 2016;10(2):109-119.

107. Gugger JJ. Antipsychotic pharmacotherapy and orthostatic hypotension: identification and management. CNS Drugs. 2011;25(8):659-671.

108. Nourian Z, Mow T, Muftic D, et al. Orthostatic hypotensive effect of antipsychotic drugs in Wistar rats by in vivo and in vitro studies of alpha1-adrenoceptor function. Psychopharmacology (Berl). 2008; 199(1):15-27.

109. Ronaldson KJ, Fitzgerald PB, McNeil JJ. Evolution of troponin, C-reactive protein and eosinophil count with the onset of clozapineinduced myocarditis. Aust N Z J Psychiatry. 2015;49(5):486-487.

110. Wassef N, Khan N, Munir S. Quetiapine-induced myocarditis presenting as acute STEMI. BMJ Case Rep. 2015;2015.

111. Roesch-Ely D, Van Einsiedel R, Kathofer S, Schwaninger M, Weisbrod M. Myocarditis with quetiapine. Am J Psychiatry. 2002; 159(9):1607-1608.

112. Nielsen J, Correll CU, Manu P, Kane JM. Termination of clozapine treatment due to medical reasons: when is it warranted and how can it be avoided? J Clin Psychiatry. 2013;74(6):603-613. quiz 613.
113. Manu P, Sarpal D, Muir O, Kane JM, Correll CU. When can patients with potentially life-threatening adverse effects be rechallenged with clozapine? A systematic review of the published literature. Schizophr Res. 2012;134(2-3):180-186.

114. Youssef DL, Narayanan P, Gill N. Incidence and risk factors for clozapine-induced myocarditis and cardiomyopathy at a regional mental health service in Australia. Australas Psychiatry. 2016;24(2): $176-180$

115. Wu Q, Kling JM. Depression and the risk of myocardial infarction and coronary death: a meta-analysis of prospective cohort studies. Medicine (Baltimore). 2016;95(6):e2815.

116. Prieto ML, Cuellar-Barboza AB, Bobo WV, et al. Risk of myocardial infarction and stroke in bipolar disorder: a systematic review and exploratory meta-analysis. Acta Psychiatr Scand. 2014;130(5):342-353.

117. Fan Z, Wu Y, Shen J, Ji T, Zhan R. Schizophrenia and the risk of cardiovascular diseases: a meta-analysis of thirteen cohort studies. J Psychiatr Res. 2013;47(11):1549-1556.

118. Li M, Fan YL, Tang ZY, Cheng XS. Schizophrenia and risk of stroke: a meta-analysis of cohort studies. Int J Cardiol. 2014;173(3):588-590.

119. Hsu W, Esmaily-Fard A, Lee C. Antipsychotic exposure and risk of stroke: a systematic review and meta-analysis of observational studies. Value Health. 2015;18(7):A828.

120. Yu ZH, Jiang HY, Shao L, Zhou YY, Shi HY, Ruan B. Use of antipsychotics and risk of myocardial infarction: a systematic review and meta-analysis. Br J Clin Pharmacol. 2016;82(3):624-632.

121. Jackson JW, Schneeweiss S, VanderWeele TJ, Blacker D. Quantifying the role of adverse events in the mortality difference between first and second-generation antipsychotics in older adults: systematic review and meta-synthesis. PLoS One. 2014;9(8):e105376.

122. Shin JY, Choi NK, Jung SY, Lee J, Kwon JS, Park BJ. Risk of ischemic stroke with the use of risperidone, quetiapine and olanzapine in elderly patients: a population-based, case-crossover study. J Psychopharmacol. 2013;27(7):638-644.

123. Shin J-Y, Choi N-K, Lee J, et al. Risk of ischemic stroke associated with the use of antipsychotic drugs in elderly patients: a retrospective cohort study in Korea. PLoS One. 2015;10(3):e0119931.

124. Pasternak B, Svanstrom H, Ranthe MF, Melbye M, Hviid A. Atypical antipsychotics olanzapine, quetiapine, and risperidone and risk of acute major cardiovascular events in young and middle-aged adults: a nationwide register-based cohort study in Denmark. CNS Drugs. 2014;28(10):963-973.

125. Layton D, Harris S, Wilton LV, Shakir SA. Comparison of incidence rates of cerebrovascular accidents and transient ischaemic attacks in observational cohort studies of patients prescribed risperidone, quetiapine or olanzapine in general practice in England including patients with dementia. J Psychopharmacol. 2005;19(5): 473-482.

126. Correll CU, Joffe BI, Rosen LM, Sullivan TB, Joffe RT. Cardiovascular and cerebrovascular risk factors and events associated with second-generation antipsychotic compared to antidepressant use in a non-elderly adult sample: results from a claims-based inception cohort study. World Psychiatry. 2015;14(1):56-63.

127. Bou Khalil R. Atypical antipsychotic drugs, schizophrenia, and metabolic syndrome in non-Euro-American societies. Clin Neuropharmacol. 2012;35(3):141-147.

128. Morissette P, Hreiche R, Mallet L, Vo D, Knaus EE, Turgeon J Olanzapine prolongs cardiac repolarization by blocking the rapid component of the delayed rectifier potassium current. J Psychopharmacol. 2007;21(7):735-741.

129. Gluais P, Bastide M, Grandmougin D, Fayad G, Adamantidis M. Risperidone reduces $\mathrm{K}+$ currents in human atrial myocytes and prolongs repolarization in human myocardium. Eur J Pharmacol. 2004; 497(2):215-222.

130. Shiga T, Yong S, Carino J, Murray PA, Damron DS. Droperidol inhibits intracellular $\mathrm{Ca} 2+$, myofilament $\mathrm{Ca} 2+$ sensitivity, and contraction in rat ventricular myocytes. Anesthesiology. 2005;102(6): $1165-1173$. 
131. Hung GC, Liu HC, Yang SY, et al. Antipsychotic reexposure and recurrent pneumonia in schizophrenia: a nested case-control study. J Clin Psychiatry. 2016;77(1):60-66.

132. Yang SY, Liao YT, Liu HC, Chen WJ, Chen CC, Kuo CJ. Antipsychotic drugs, mood stabilizers, and risk of pneumonia in bipolar disorder: a nationwide case-control study. J Clin Psychiatry. 2013; 74(1):e79-e86.

133. Hinkes R, Quesada TV, Currier MB, Gonzalez-Blanco M. Aspiration pneumonia possibly secondary to clozapine-induced sialorrhea. J Clin Psychopharmacol. 1996;16(6):462-463.

134. Gambassi G, Sultana J, Trifiro G. Antipsychotic use in elderly patients and the risk of pneumonia. Expert Opin Drug Saf. 2015;14(1):1-6.

135. Mehta S, Pulungan Z, Jones BT, Teigland C. Comparative safety of atypical antipsychotics and the risk of pneumonia in the elderly. Pharmacoepidemiol Drug Saf. 2015;24(12):1271-1280.

136. Nose M, Recla E, Trifiro G, Barbui C. Antipsychotic drug exposure and risk of pneumonia: a systematic review and meta-analysis of observational studies. Pharmacoepidemiol Drug Saf. 2015;24(8): 812-820.

137. Jackson JW, VanderWeele TJ, Blacker D, Schneeweiss S. Mediators of first- versus second-generation antipsychotic-related mortality in older adults. Epidemiology. 2015;26(5):700-709.

138. Stubbs B, Vancampfort D, Veronese N, et al. The prevalence and predictors of obstructive sleep apnea in major depressive disorder, bipolar disorder and schizophrenia: a systematic review and metaanalysis. J Affect Disord. 2016;197:259-267.

139. Oud MJ, Meyboom-de Jong B. Somatic diseases in patients with schizophrenia in general practice: their prevalence and health care. BMC Fam Pract. 2009;10:32.

140. Wang MT, Tsai CL, Lin CW, Yeh CB, Wang YH, Lin HL. Association between antipsychotic agents and risk of acute respiratory failure in patients with chronic obstructive pulmonary disease. JAMA Psychiatry. 2017;74(3):252-260

141. Minns AB, Clark RF. Toxicology and overdose of atypical antipsychotics. J Emerg Med. 2012;43(5):906-913.

142. Rishi MA, Shetty M, Wolff A, Amoateng-Adjepong Y, Manthous CA. Atypical antipsychotic medications are independently associated with severe obstructive sleep apnea. Clin Neuropharmacol. 2010;33(3):109-113.

143. Chow V, Reddel C, Pennings G, et al. Global hypercoagulability in patients with schizophrenia receiving long-term antipsychotic therapy. Schizophr Res. 2015;162(1-3):175-182.

144. Conti V, Venegoni M, Cocci A, Fortino I, Lora A, Barbui C. Antipsychotic drug exposure and risk of pulmonary embolism: a populationbased, nested case-control study. BMC Psychiatry. 2015;15:92.

145. Barbui C, Conti V, Cipriani A. Antipsychotic drug exposure and risk of venous thromboembolism: a systematic review and meta-analysis of observational studies. Drug Saf. 2014;37(2):79-90.

146. Parker C, Coupland C, Hippisley-Cox J. Antipsychotic drugs and risk of venous thromboembolism: nested case-control study. BMJ. 2010; 341:c4245.

147. Parkin L, Skegg DC, Herbison GP, Paul C. Psychotropic drugs and fatal pulmonary embolism. Pharmacoepidemiol Drug Saf. 2003; 12(8):647-652.

148. Every-Palmer S, Nowitz M, Stanley J, et al. Clozapine-treated patients have marked gastrointestinal hypomotility, the probable basis of lifethreatening gastrointestinal complications: a cross sectional study. EBioMedicine. 2016;5:125-134

149. Ozbilen M, Adams CE, Marley J. Anticholinergic effects of oral antipsychotic drugs of typicals versus atypicals over medium- and longterm: systematic review and meta-analysis. Curr Med Chem. 2012; 19(30):5214-5218.

150. Stubbs B, Thompson T, Acaster S, Vancampfort D, Gaughran F, Correll CU. Decreased pain sensitivity among people with schizophrenia: a meta-analysis of experimental pain induction studies. Pain. 2015;156(11):2121-2131.
151. Shirazi A, Stubbs B, Gomez L, et al. Prevalence and predictors of clozapine-associated constipation: a systematic review and metaanalysis. Int J Mol Sci. 2016;17(6).

152. Harrington CA, English C. Tolerability of paliperidone: a metaanalysis of randomized, controlled trials. Int Clin Psychopharmacol. 2010;25(6):334-341.

153. Galling B, Roldan A, Rietschel L, et al. Safety and tolerability of antipsychotic co-treatment in patients with schizophrenia: results from a systematic review and meta-analysis of randomized controlled trials. Expert Opin Drug Saf. 2016;15(5):591-612.

154. Fleischhacker WW, Sanchez R, Johnson B, et al. Long-term safety and tolerability of aripiprazole once-monthly in maintenance treatment of patients with schizophrenia. Int Clin Psychopharmacol. 2013; 28(4):171-176.

155. Citrome L. Cariprazine in schizophrenia: clinical efficacy, tolerability, and place in therapy. Adv Ther. 2013;30(2):114-126.

156. Hu KF, Chou YH, Wen YH, et al. Antipsychotic medications and dental caries in newly diagnosed schizophrenia: a nationwide cohort study. Psychiatry Res. 2016;245:45-50.

157. Li XB, Tang YL, Wang CY, de Leon J. Clozapine for treatmentresistant bipolar disorder: a systematic review. Bipolar Disord. 2015; 17(3):235-247.

158. Marwick KF, Taylor M, Walker SW. Antipsychotics and abnormal liver function tests: systematic review. Clin Neuropharmacol. 2012; 35(5):244-253.

159. Atasoy N, Erdogan A, Yalug I, et al. A review of liver function tests during treatment with atypical antipsychotic drugs: a chart review study. Prog Neuropsychopharmacol Biol Psychiatry. 2007;31(6): 1255-1260.

160. Dumortier G, Cabaret W, Stamatiadis L, et al. Tolérance hépatique des antipsychotiques atypiques [Hepatic tolerance of atypical antipsychotic drugs]. Encephale. 2002;28(6 pt 1):542-551.

161. Hsu JH, Chien IC, Lin CH. Increased risk of chronic liver disease in patients with bipolar disorder: a population-based study. Gen Hosp Psychiatry. 2016;42:54-59.

162. Morlan-Coarasa MJ, Arias-Loste MT, Ortiz-Garcia de la Foz V, et al. Incidence of non-alcoholic fatty liver disease and metabolic dysfunction in first episode schizophrenia and related psychotic disorders: a 3-year prospective randomized interventional study. Psychopharmacology (Berl). 2016;233(23-24):3947-3952.

163. Slim M, Medina-Caliz I, Gonzalez-Jimenez A, et al. Hepatic safety of atypical antipsychotics: current evidence and future directions. Drug Saf. 2016;39(10):925-943.

164. Fountoulakis KN, Grunze H, Vieta E, et al. The International College of Neuro-Psychopharmacology (CINP) treatment guidelines for bipolar disorder in adults (CINP-BD-2017), part 3: the clinical guidelines. Int J Neuropsychopharmacol. 2017;20(2):98-120.

165. Scarff JR. Cariprazine for schizophrenia and bipolar disorder. Innov Clin Neurosci. 2016;13(9-10):49-52.

166. Faure Walker N, Brinchmann K, Batura D. Linking the evidence between urinary retention and antipsychotic or antidepressant drugs: a systematic review. Neurourol Urodyn. 2016;35(8): 866-874.

167. Hwang YJ, Dixon SN, Reiss JP, et al. Atypical antipsychotic drugs and the risk for acute kidney injury and other adverse outcomes in older adults: a population-based cohort study. Ann Intern Med. 2014; 161(4):242-248.

168. Verhamme KM, Sturkenboom MC, Stricker BH, Bosch R. Druginduced urinary retention: incidence, management and prevention. Drug Saf. 2008;31(5):373-388.

169. Barnes TR, Drake MJ, Paton C. Nocturnal enuresis with antipsychotic medication. Br J Psychiatry. 2012;200(1):7-9.

170. Goodwin GM, Haddad PM, Ferrier IN, et al. Evidence-based guidelines for treating bipolar disorder: revised third edition recommendations from the British Association for Psychopharmacology. J Psychopharmacol. 2016;30(6):495-553. 
171. Bulut SD, Bulut S, Atalan DG, et al. The effect of antipsychotics on bone mineral density and sex hormones in male patients with schizophrenia. Psychiatr Danub. 2016;28(3):255-262.

172. Kishimoto T, De Hert M, Carlson HE, Manu P, Correll CU. Osteoporosis and fracture risk in people with schizophrenia. Curr Opin Psychiatry. 2012;25(5):415-429.

173. Stubbs B, De Hert M, Sepehry AA, et al. A meta-analysis of prevalence estimates and moderators of low bone mass in people with schizophrenia. Acta Psychiatr Scand. 2014;130(6):470-486.

174. Gomez L, Stubbs B, Shirazi A, Vancampfort D, Gaughran F, Lally J. Lower bone mineral density at the hip and lumbar spine in people with psychosis versus controls: a comprehensive review and skeletal site-specific meta-analysis. Curr Osteoporos Rep. 2016;14(6): 249-259.

175. Zhang B, Deng L, Wu H, et al. Relationship between long-term use of a typical antipsychotic medication by Chinese schizophrenia patients and the bone turnover markers serum osteocalcin and betaCrossLaps. Schizophr Res. 2016;176(2-3):259-263.

176. De Hert M, Detraux J, Stubbs B. Relationship between antipsychotic medication, serum prolactin levels and osteoporosis/osteoporotic fractures in patients with schizophrenia: a critical literature review. Expert Opin Drug Saf. 2016;15(6):809-823.

177. Stubbs B, Gaughran F, Mitchell AJ, et al. Schizophrenia and the risk of fractures: a systematic review and comparative meta-analysis. Gen Hosp Psychiatry. 2015;37(2):126-133.

178. Torstensson M, Leth-Moller K, Andersson C, Torp-Pedersen C, Gislason GH, Holm EA. Danish register-based study on the association between specific antipsychotic drugs and fractures in elderly individuals. Age Ageing. 2017;46(2):258-264.

179. Wei YJ, Simoni-Wastila L, Lucas JA, Brandt N. Fall and fracture risk in nursing home residents with moderate-to-severe behavioral symptoms of Alzheimer's disease and related dementias initiating antidepressants or antipsychotics. J Gerontol A Biol Sci Med Sci. 2016;72(5):695-702.

180. Berry SD, Placide SG, Mostofsky E, et al. Antipsychotic and benzodiazepine drug changes affect acute falls risk differently in the nursing home. J Gerontol A Biol Sci Med Sci. 2016;71(2):273-278.

181. Kluge M, Schuld A, Himmerich H, et al. Clozapine and olanzapine are associated with food craving and binge eating: results from a randomized double-blind study. J Clin Psychopharmacol. 2007; 27(6):662-666.

182. Etminan M, Sodhi M, Samii A, Procyshyn RM, Guo M, Carleton BC. Risk of gambling disorder and impulse control disorder with aripiprazole, pramipexole, and ropinirole: a pharmacoepidemiologic study. J Clin Psychopharmacol. 2017;37(1):102-104.

183. Moore TJ, Glenmullen J, Mattison DR. Reports of pathological gambling, hypersexuality, and compulsive shopping associated with dopamine receptor agonist drugs. JAMA Intern Med. 2014;174(12):1930-1933.

184. Gaboriau L, Victorri-Vigneau C, Gerardin M, Allain-Veyrac G, Jolliet-Evin P, Grall-Bronnec M. Aripiprazole: a new risk factor for pathological gambling? A report of 8 case reports. Addict Behav. 2014; 39(3):562-565.

185. Friedman JH, Berman RM, Goetz CG, et al. Open-label flexible-dose pilot study to evaluate the safety and tolerability of aripiprazole in patients with psychosis associated with Parkinson's disease. Mov Disord. 2006;21(12):2078-2081.

186. Grall-Bronnec M, Sauvaget A, Perrouin F, et al. Pathological gambling associated with aripiprazole or dopamine replacement therapy: do patients share the same features? A Review. J Clin Psychopharmacol. 2016;36(1):63-70.

187. Wu BJ, Chen HK, Lee SM. Do atypical antipsychotics really enhance smoking reduction more than typical ones? The effects of antipsychotics on smoking reduction in patients with schizophrenia. J Clin Psychopharmacol. 2013;33(3):319-328.

188. Wu BJ, Lan TH. Predictors of smoking reduction outcomes in a sample of 287 patients with schizophrenia spectrum disorders. Eur Arch Psychiatry Clin Neurosci. 2017;267(1):63-72.
189. Heffner JL, Strawn JR, DelBello MP, Strakowski SM, Anthenelli RM. The co-occurrence of cigarette smoking and bipolar disorder: phenomenology and treatment considerations. Bipolar Disord. 2011; 13(5-6):439-453.

190. Featherstone RE, Siegel SJ. The role of nicotine in schizophrenia. Int Rev Neurobiol. 2015;124:23-78.

191. Gallego JA, Nielsen J, De Hert M, Kane JM, Correll CU. Safety and tolerability of antipsychotic polypharmacy. Expert Opin Drug Saf. 2012;11(4):527-542.

192. Lee JY, Kim SW, Lee YH, et al. Factors associated with self-rated sexual function in Korean patients with schizophrenia receiving risperidone monotherapy. Hum Psychopharmacol. 2015;30(6):416-424.

193. Wirshing DA, Pierre JM, Marder SR, Saunders CS, Wirshing WC. Sexual side effects of novel antipsychotic medications. Schizophr Res. 2002;56(1-2):25-30.

194. Montejo AL, Montejo L, Navarro-Cremades F. Sexual side-effects of antidepressant and antipsychotic drugs. Curr Opin Psychiatry. 2015; 28(6):418-423.

195. Pacchiarotti I, Leon-Caballero J, Murru A, et al. Mood stabilizers and antipsychotics during breastfeeding: focus on bipolar disorder. Eur Neuropsychopharmacol. 2016;26(10):1562-1578.

196. Compton MT, Miller AH. Antipsychotic-induced hyperprolactinemia and sexual dysfunction. Psychopharmacol Bull. 2002;36(1):143-164.

197. Compton MT, Miller AH. Priapism associated with conventional and atypical antipsychotic medications: a review. J Clin Psychiatry. 2001;62(5):362-366.

198. Loh C, Leckband SG, Meyer JM, Turner E. Risperidone-induced retrograde ejaculation: case report and review of the literature. Int Clin Psychopharmacol. 2004;19(2):111-112.

199. Just MJ. The influence of atypical antipsychotic drugs on sexual function. Neuropsychiatr Dis Treat. 2015;11:1655-1661.

200. Jin H, Meyer JM, Jeste DV. Phenomenology of and risk factors for new-onset diabetes mellitus and diabetic ketoacidosis associated with atypical antipsychotics: an analysis of 45 published cases. Ann Clin Psychiatry. 2002;14(1):59-64.

201. Polcwiartek C, Vang T, Bruhn CH, Hashemi N, Rosenzweig M, Nielsen J. Diabetic ketoacidosis in patients exposed to antipsychotics: a systematic literature review and analysis of Danish adverse drug event reports. Psychopharmacology (Berl). 2016;233(21-22):3663-3672.

202. Lambert CG, Mazurie AJ, Lauve NR, et al. Hypothyroidism risk compared among nine common bipolar disorder therapies in a large US cohort. Bipolar Disord. 2016;18(3):247-260.

203. Kelly DL, Conley RR. Thyroid function in treatment-resistant schizophrenia patients treated with quetiapine, risperidone, or fluphenazine. J Clin Psychiatry. 2005;66(1):80-84.

204. Mannesse CK, van Puijenbroek EP, Jansen PA, van Marum RJ, Souverein PC, Egberts TC. Hyponatraemia as an adverse drug reaction of antipsychotic drugs: a case-control study in VigiBase. Drug Saf. 2010;33(7):569-578.

205. Yamada K, Shinkai T, Chen HI, Utsunomiya K, Nakamura J. Effect of COMT Val108/158Met genotype on risk for polydipsia in chronic patients with schizophrenia. Neuromolecular Med. 2014;16(2):398-404.

206. Tsuboi T, Bies RR, Suzuki T, et al. Hyperprolactinemia and estimated dopamine D2 receptor occupancy in patients with schizophrenia: analysis of the CATIE data. Prog Neuropsychopharmacol Biol Psychiatry. 2013;45:178-182.

207. Carboni L, Negri M, Michielin F, et al. Slow dissociation of partial agonists from the $\mathrm{D}(2)$ receptor is linked to reduced prolactin release. Int J Neuropsychopharmacol. 2012;15(5):645-656.

208. Montejo AL, Arango C, Bernardo M, et al. Spanish consensus on the risks and detection of antipsychotic drug-related hyperprolactinaemia. Rev Psiquiatr Salud Ment. 2016;9(3):158-173.

209. Pacchiarotti I, Murru A, Kotzalidis GD, et al. Hyperprolactinemia and medications for bipolar disorder: systematic review of a neglected issue in clinical practice. Eur Neuropsychopharmacol. 2015;25(8): 1045-1059. 
210. Chen JX, Su YA, Bian QT, et al. Adjunctive aripiprazole in the treatment of risperidone-induced hyperprolactinemia: a randomized, double-blind, placebo-controlled, dose-response study. Psychoneuroendocrinology. 2015;58:130-140.

211. Chen CY, Lin TY, Wang CC, Shuai HA. Improvement of serum prolactin and sexual function after switching to aripiprazole from risperidone in schizophrenia: a case series. Psychiatry Clin Neurosci. 2011;65(1):95-97.

212. Melkersson K, Hulting AL. Prolactin-secreting pituitary adenoma in neuroleptic treated patients with psychotic disorder. Eur Arch Psychiatry Clin Neurosci. 2000;250(1):6-10.

213. Perroud N, Huguelet P. A possible effect of amisulpride on a prolactinoma growth in a woman with borderline personality disorder. Pharmacol Res. 2004;50(3):377-379.

214. Akkaya C, Kaya B, Kotan Z, Sarandol A, Ersoy C, Kirli S. Hyperprolactinemia and possibly related development of prolactinoma during amisulpride treatment; three cases. J Psychopharmacol. 2009; 23(6):723-726.

215. Pal JK, Sarino WA. Effect of risperidone on prolactinoma growth in a psychotic woman. Psychosom Med. 2000;62(5):736-738.

216. Mendhekar DN, Jiloha RC, Srivastava PK. Effect of risperidone on prolactinoma - a case report. Pharmacopsychiatry. 2004;37(1):41-42.

217. Arcari GT, Mendes AK, Sothern RB. A risperidone-induced prolactinoma resolved when a woman with schizoaffective disorder switched to ziprasidone: a case report. Innov Clin Neurosci. 2012;9(9):21-24.

218. Montejo AL, Arango C, Bernardo M, et al. Multidisciplinary consensus on the therapeutic recommendations for iatrogenic hyperprolactinemia secondary to antipsychotics. Front Neuroendocrinol. 2017;45:25-34.

219. Baller JB, McGinty EE, Azrin ST, Juliano-Bult D, Daumit GL. Screening for cardiovascular risk factors in adults with serious mental illness: a review of the evidence. BMC Psychiatry. 2015;15:55.

220. Mo PK, Mak WW, Chong ES, Shen H, Cheung RY. The prevalence and factors for cancer screening behavior among people with severe mental illness in Hong Kong. PLoS One. 2014;9(9):e107237.

221. Ribe AR, Laurberg T, Laursen TM, Charles M, Vedsted P, VestergaardM. Ten-year mortality after a breast cancer diagnosis in women with severe mental illness: a Danish population-based cohort study. PLoS One. 2016;11(7):e0158013.

222. Osborn DP, Levy G, Nazareth I, Petersen I, Islam A, King MB. Relative risk of cardiovascular and cancer mortality in people with severe mental illness from the United Kingdom's General Practice Rsearch Database. Arch Gen Psychiatry. 2007;64(2):242-249.

223. Ji J, Sundquist K, Ning Y, Kendler KS, Sundquist J, Chen X. Incidence of cancer in patients with schizophrenia and their first-degree relatives: a population-based study in Sweden. Schizophr Bull. 2013; 39(3):527-536.

224. De Hert M, Vancampfort D, Stubbs B, Sabbe T, Wildiers H, Detraux J. Antipsychotic treatment, prolactin, and breast tumorigenesis. Psychiatr Danub. 2016;28(3):243-254.

225. De Hert M, Peuskens J, Sabbe T, et al. Relationship between prolactin, breast cancer risk, and antipsychotics in patients with schizophrenia: a critical review. Acta Psychiatr Scand. 2016;133(1):5-22.

226. Reutfors J, Wingard L, Brandt L, et al. Risk of breast cancer in risperidone users: a nationwide cohort study. Schizophr Res. 2017; 182:98-103.

227. Fond G, Macgregor A, Attal J, et al. Antipsychotic drugs: pro-cancer or anti-cancer? A systematic review. Med Hypotheses. 2012;79(1): 38-42.

228. Caroff SN. The neuroleptic malignant syndrome. J Clin Psychiatry. 1980;41(3):79-83.

229. Gurrera RJ, Simpson JC, Tsuang MT. Meta-analytic evidence of systematic bias in estimates of neuroleptic malignant syndrome incidence. Compr Psychiatry. 2007;48(2):205-211.

230. Tse L, Barr AM, Scarapicchia V, Vila-Rodriguez F. Neuroleptic malignant syndrome: a review from a clinically oriented perspective. Curr Neuropharmacol. 2015;13(3):395-406.
231. Belvederi Murri M, Guaglianone A, Bugliani M, et al. Second-generation antipsychotics and neuroleptic malignant syndrome: systematic review and case report analysis. Drugs R D. 2015;15(1):45-62.

232. Neuhut R, Lindenmayer JP, Silva R. Neuroleptic malignant syndrome in children and adolescents on atypical antipsychotic medication: a review. J Child Adolesc Psychopharmacol. 2009;19(4):415-422.

233. Weinmann S, Read J, Aderhold V. Influence of antipsychotics on mortality in schizophrenia: systematic review. Schizophr Res. 2009; 113(1):1-11.

234. Seeman P. Targeting the dopamine D2 receptor in schizophrenia. Expert Opin Ther Targets. 2006;10(4):515-531.

235. Cerovecki A, Musil R, Klimke A, et al. Withdrawal symptoms and rebound syndromes associated with switching and discontinuing atypical antipsychotics: theoretical background and practical recommendations. CNS Drugs. 2013;27(7):545-572.

236. Gentile S. Antipsychotic therapy during early and late pregnancy. A systematic review. Schizophr Bull. 2010;36(3):518-544.

237. Habermann F, Fritzsche J, Fuhlbruck F, et al. Atypical antipsychotic drugs and pregnancy outcome: a prospective, cohort study. J Clin Psychopharmacol. 2013;33(4):453-462.

238. Vigod SN, Gomes T, Wilton AS, Taylor VH, Ray JG. Antipsychotic drug use in pregnancy: high dimensional, propensity matched, population based cohort study. BMJ. 2015;350:h2298.

239. Larsen ER, Damkier P, Pedersen LH, et al. Use of psychotropic drugs during pregnancy and breast-feeding. Acta Psychiatr Scand Suppl. 2015;132(445):1-28.

240. Huybrechts KF, Hernandez-Diaz S, Patorno E, et al. Antipsychotic use in pregnancy and the risk for congenital malformations. JAMA Psychiatry. 2016;73(9):938-946.

241. Cohrs S. Sleep disturbances in patients with schizophrenia: impact and effect of antipsychotics. CNS Drugs. 2008;22(11):939-962.

242. Kreuzer P, Landgrebe M, Wittmann M, et al. Hypothermia associated with antipsychotic drug use: a clinical case series and review of current literature. J Clin Pharmacol. 2012;52(7):1090-1097.

243. Kane JM, Correll CU. Past and present progress in the pharmacologic treatment of schizophrenia. J Clin Psychiatry. 2010;71(9): 1115-1124.

244. Correll CU. Acute and long-term adverse effects of antipsychotics. CNS Spectr. 2007;12(12 suppl 21):10-14.

245. Caemmerer J, Correll CU, Maayan L. Acute and maintenance effects of non-pharmacologic interventions for antipsychotic associated weight gain and metabolic abnormalities: a meta-analytic comparison of randomized controlled trials. Schizophr Res. 2012;140(1-3):159-168.

246. Mizuno Y, Suzuki T, Nakagawa A, et al. Pharmacological strategies to counteract antipsychotic-induced weight gain and metabolic adverse effects in schizophrenia: a systematic review and meta-analysis. Schizophr Bull. 2014;40(6):1385-1403.

247. Pearsall R, Thyarappa Praveen K, Pelosi A, Geddes J. Dietary advice for people with schizophrenia. Cochrane Database Syst Rev. 2016;3: CD009547.

248. Pearsall R, Smith DJ, Pelosi A, Geddes J. Exercise therapy in adults with serious mental illness: a systematic review and meta-analysis. BMC Psychiatry. 2014;14:117.

249. Gierisch JM, Nieuwsma JA, Bradford DW, et al. Pharmacologic and behavioral interventions to improve cardiovascular risk factors in adults with serious mental illness: a systematic review and metaanalysis. J Clin Psychiatry. 2014;75(5):e424-e440.

250. Speyer H, Christian Brix Norgaard H, Birk M, et al. The CHANGE trial: no superiority of lifestyle coaching plus care coordination plus treatment as usual compared to treatment as usual alone in reducing risk of cardiovascular disease in adults with schizophrenia spectrum disorders and abdominal obesity. World Psychiatry. 2016;15(2):155-165.

251. Stahl SM, Malla A, Newcomer JW, et al. A post hoc analysis of negative symptoms and psychosocial function in patients with schizophrenia: a 40-week randomized, double-blind study of ziprasidone versus haloperidol followed by a 3-year double-blind extension trial. J Clin Psychopharmacol. 2010;30(4):425-430. 
252. Colom F, Vieta E, Daban C, Pacchiarotti I, Sanchez-Moreno J. Clinical and therapeutic implications of predominant polarity in bipolar disorder. J Affect Disord. 2006;93(1-3):13-17.

253. Calabrese JR, Hirschfeld RM, Frye MA, Reed ML. Impact of depressive symptoms compared with manic symptoms in bipolar disorder: results of a U.S. community-based sample. J Clin Psychiatry. 2004; 65(11):1499-1504.

254. Grande I, Berk M, Birmaher B, Vieta E. Bipolar disorder. Lancet. 2016;387(10027):1561-1572.

255. Popovic D, Reinares M, Goikolea JM, Bonnin CM, Gonzalez-Pinto A, Vieta E. Polarity index of pharmacological agents used for maintenance treatment of bipolar disorder. Eur Neuropsychopharmacol. 2012;22(5):339-346.

256. Carvalho AF, Quevedo J, McIntyre RS, et al. Treatment implications of predominant polarity and the polarity index: a comprehensive review. Int $J$ Neuropsychopharmacol. 2014;18(2).

257. Murru A, Pacchiarotti I, Amann BL, Nivoli AM, Vieta E, Colom F. Treatment adherence in bipolar I and schizoaffective disorder, bipolar type. J Affect Disord. 2013;151(3):1003-1008.

258. Rosa AR, Andreazza AC, Kunz M, et al. Predominant polarity in bipolar disorder: diagnostic implications. J Affect Disord. 2008; 107(1-3):45-51.
259. Grunze H, Vieta E, Goodwin GM, et al. The World Federation of Societies of Biological Psychiatry (WFSBP) guidelines for the biological treatment of bipolar disorders: update 2012 on the long-term treatment of bipolar disorder. World J Biol Psychiatry. 2013;14(3):154-219.

260. Hasan A, Falkai P, Wobrock T, et al. World Federation of Societies of Biological Psychiatry (WFSBP) guidelines for biological treatment of schizophrenia, part 2: update 2012 on the long-term treatment of schizophrenia and management of antipsychotic-induced side effects. World J Biol Psychiatry. 2013;14(1):2-44.

261. Barnes TR. Schizophrenia Consensus Group of British Association for P. Evidence-based guidelines for the pharmacological treatment of schizophrenia: recommendations from the British Association for Psychopharmacology. J Psychopharmacol. 2011;25(5):567-620.

262. Fleeman N, Dundar Y, Dickson R, et al. Cytochrome P450 testing for prescribing antipsychotics in adults with schizophrenia: systematic review and meta-analyses. Pharmacogenomics J. 2011;11(1):1-14.

263. Vieta E. La medicina personalizada aplicada a la salud mental: la psiquiatría de precisión [Personalised medicine applied to mental health: precision psychiatry]. Rev Psiquiatr Salud Ment 2015;8(3):117-118.
Therapeutics and Clinical Risk Management

\section{Publish your work in this journal}

Therapeutics and Clinical Risk Management is an international, peerreviewed journal of clinical therapeutics and risk management, focusing on concise rapid reporting of clinical studies in all therapeutic areas, outcomes, safety, and programs for the effective, safe, and sustained use of medicines. This journal is indexed on PubMed Central, CAS,

\section{Dovepress}

EMBase, Scopus and the Elsevier Bibliographic databases. The manuscript management system is completely online and includes a very quick and fair peer-review system, which is all easy to use. Visit http://www.dovepress.com/testimonials.php to read real quotes from published authors.

Submit your manuscript here: http://www.dovepress.com/therapeutics-and-clinical-risk-management-journal 